( ) 2018. This manuscript version is made available under the CC-BY-NC-ND 4.0 license http:/creativecommons.org/licenses/by-nc-nd/4.0/

\title{
Regeneration of Sulfur-Poisoned Pd-based Catalyst for Natural Gas Oxidation
}

Mari Honkanen ${ }^{\mathrm{a},{ }^{*},}$, Jianguang Wang ${ }^{\mathrm{b}}$, Marja Kärkkäinen ${ }^{\mathrm{c}}$, Mika Huuhtanen ${ }^{\mathrm{c}}$, Hua Jiang ${ }^{\mathrm{d}}$, Kauko Kallinen $^{\mathrm{e}}$, Riitta L. Keiskic, Jaakko Akola ${ }^{\text {b,f }}$, Minnamari Vippola ${ }^{\mathrm{a}}$

${ }^{(a)}$ Materials Science, Tampere University of Technology, Tampere, Finland

(b) Physics, Tampere University of Technology, Tampere, Finland

${ }^{(c)}$ Environmental and Chemical Engineering, University of Oulu, Oulu, Finland

${ }^{(d)}$ Department of Applied Physics, Aalto University, Espoo, Finland

${ }^{(e)}$ Dinex Ecocat Oy, Vihtavuori, Finland

${ }^{(f)}$ Department of Physics, Norwegian University of Science and Technology, Trondheim, Norway

${ }^{(*)}$ Corresponding author, email: mari.honkanen@tut.fi, telephone: +358408490133

Co-authors’ e-mails: Jianguang Wang: jianguang.wang@tut.fi Marja Kärkkäinen: marja.karkkainen@oulu.fi

Mika Huuhtanen: mika.huuhtanen@oulu.fi

Hua Jiang: hua.jiang@aalto.fi

Kauko Kallinen:kki@dinex.fi

Riitta L. Keiski: riitta.keiski@oulu.fi

Jaakko Akola: jaakko.akola@tut.fi

Minnamari Vippola: minnamari.vippola@tut.fi

\section{Abstract}

Sulfur deactivation and regeneration behavior of the $\mathrm{Pd} / \mathrm{Al}_{2} \mathrm{O}_{3}$ catalyst has been investigated via experimental characterization and density functional theory (DFT) simulations. During the sulfur exposure, $\mathrm{PdO}$ crystallites grow slightly while bulk $\mathrm{Al}_{2}\left(\mathrm{SO}_{4}\right)_{3}$ forms on the support. DFT calculations indicate that $\mathrm{SO}_{\mathrm{x}}$ species interact strongly with the catalyst surface making it chemically inactive in agreement with the experimental results. During the regeneration treatment $\left(\mathrm{CH}_{4}\right.$ conditions $), \mathrm{PdO}$ particles reduce, $\mathrm{Al}_{2}\left(\mathrm{SO}_{4}\right)_{3}$ is partially removed, and the activity for $\mathrm{CH}_{4}$ conversion is increased. No full recovery can be observed due to remaining $\mathrm{Al}_{2}\left(\mathrm{SO}_{4}\right)_{3}$, the formation of encapsulating sulfur species, and the partial reduction of $\mathrm{PdO}$ particles. To reoxidize $\mathrm{Pd}$, the catalyst is further regenerated $\left(\mathrm{O}_{2}\right.$ conditions $)$. The resulting $\mathrm{CH}_{4}$ conversion is at the same level than with the regenerated catalyst. Thus, a small amount of $\mathrm{Al}_{2}\left(\mathrm{SO}_{4}\right)_{3}$ appears to have a stronger effect on the performance than the state of $\mathrm{Pd}$.

\section{Keywords}

Pd-based catalyst, sulfur poisoning, regeneration, transmission electron microscopy, Fourier transform

infrared spectrometry, catalytic testing, density functional theory simulations 

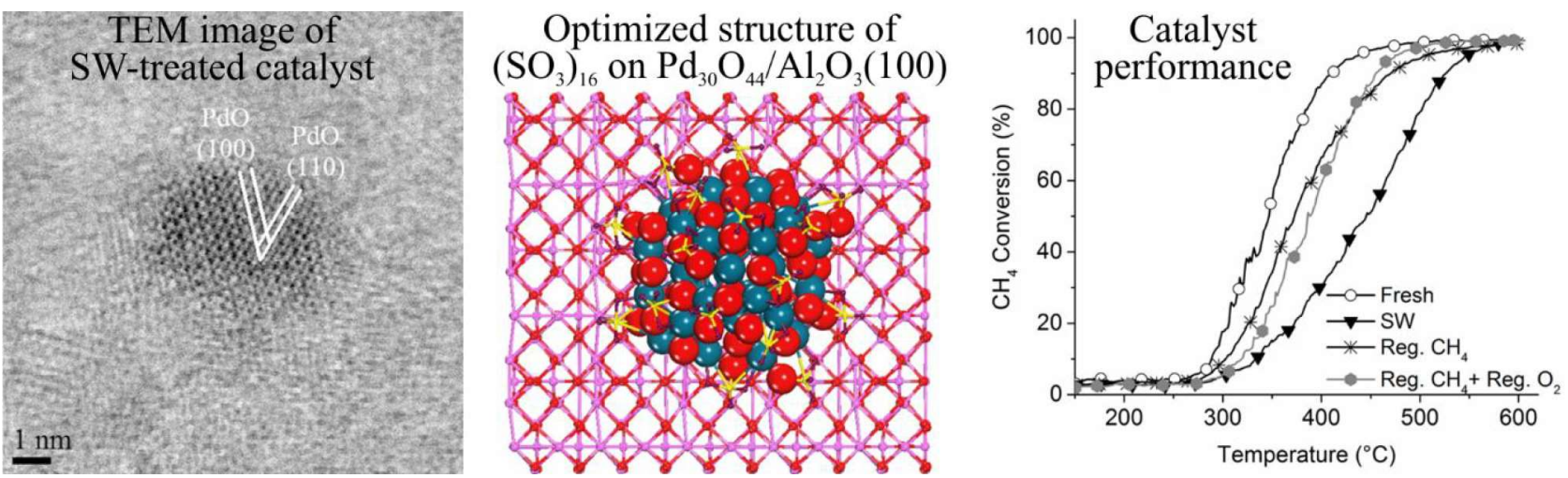

45

46

$47 \quad$ Highlights

48

- In sulfur treatment, bulk $\mathrm{Al}_{2}\left(\mathrm{SO}_{4}\right)_{3}$ forms and $\mathrm{PdO}$ size increases slightly

49

- Adsorption of $\left(\mathrm{SO}_{3}\right)_{\mathrm{n}}$ on $\mathrm{Pd}_{30} \mathrm{O}_{44} / \mathrm{Al}_{2} \mathrm{O}_{3}$ reaches saturation at $\mathrm{n}=16$

50

- $\mathrm{SO}_{3}$ encapsulated $\mathrm{Pd}_{30} \mathrm{O}_{44} / \mathrm{Al}_{2} \mathrm{O}_{3}$ is chemically inactive

- Regeneration reduces $\mathrm{PdO}$ partly to $\mathrm{Pd}$ and part of $\mathrm{Al}_{2}\left(\mathrm{SO}_{4}\right)_{3}$ is removed

52

- Remaining $\mathrm{Al}_{2}\left(\mathrm{SO}_{4}\right)_{3}$ has stronger effect on catalyst performance than state of $\mathrm{Pd}$

53

54

55

56

57

58

59

60

61

62

63

64

65

66

67

68

69

70

71 


\section{INTRODUCTION}

Transportation is one of the largest sources in air pollution, especially regarding nitrogen oxides $\left(\mathrm{NO}_{\mathrm{x}}\right)$ and particulate matters (PMs). Thus, emission reduction from vehicle engines is in the top of priority all around the world. The use of natural gas (NG) as an energy source will reduce the $\mathrm{NO}_{\mathrm{x}}$ and $\mathrm{PM}$ emissions from automotive and heavy-duty vehicles. However, exhaust gases of NG vehicles (NGVs) contain unburned methane which is identified as a strong greenhouse gas and the global warming potential of which is 75 times higher than that of $\mathrm{CO}_{2}$ [1]. Thus, methane has to be converted to less harmful compounds $\left(\mathrm{CO}_{2}\right.$ and $\left.\mathrm{H}_{2} \mathrm{O}\right)$ by a catalytic converter. $\mathrm{Pd} / \mathrm{Al}_{2} \mathrm{O}_{3}$ catalysts are widely known to be very active to combust methane. In addition, it has been concluded that PdO is the active phase while metallic $\mathrm{Pd}$ is less active [2,3]. However, the most active phase depends on the operating temperature.

Temperature of the exhaust gases from lean-burn NGV engines is typically below $500-550{ }^{\circ} \mathrm{C}[3]$. Matam et al. [4] have observed that below $677^{\circ} \mathrm{C} \mathrm{PdO}$ is the active phase for methane combustion, and therefore, $\mathrm{PdO}$ is the desirable active phase in the NGV applications.

Problems related to thermal aging and poisoning occur over supported Pd catalysts. Thermal deactivation is caused by the loss of active surface area due to the crystallite growth of noble metal particles, or the collapse of the support, and/or chemical transformations of the active catalytic phases to non-active phases [5]. While $\mathrm{PdO}$ decomposes to metallic $\mathrm{Pd}$ in the catalyst, its activity for methane conversion in the NGV applications decreases. The $\mathrm{PdO} \leftrightarrow \mathrm{Pd}$ transformation is reversible, and the decomposition of $\mathrm{PdO}$ to $\mathrm{Pd}$ in the $\mathrm{Pd} / \mathrm{Al}_{2} \mathrm{O}_{3}$ catalyst occurs at $\sim 800{ }^{\circ} \mathrm{C}$ in air, while the re-oxidation is detected upon cooling to $\sim 600{ }^{\circ} \mathrm{C}$ [2]. Hysteresis in the re-oxidation is due to strongly bound oxygen on the Pd surface inhibiting bulk oxidation [6]. Many factors, such as gas phase composition and pressure, affect the PdO $\leftrightarrow \mathrm{Pd}$ transformation [7]. For example, $\mathrm{H}_{2}$ can reduce $\mathrm{PdO}$ to metallic $\mathrm{Pd}$ in the $\mathrm{Pd} / \mathrm{Al}_{2} \mathrm{O}_{3}$ catalyst already at $100-150{ }^{\circ} \mathrm{C}$, methane at $280-290{ }^{\circ} \mathrm{C}$, and He above $700{ }^{\circ} \mathrm{C}$ [8].

Poisoning is due to the adsorption of impurities on the catalytic active sites. Poisons can also react with the active sites followed by the formation of non-active compounds [9]. In the natural gas applications, sulfur-containing compounds in the exhaust gases (originating from odorants, lubricating oils and natural gas itself) rapidly decrease the activity of the oxidation catalyst. Only a small amount of $\mathrm{SO}_{2}$ is enough to block the active noble metal sites $[3,10,11]$. While $\mathrm{SO}_{2}$ and water are present simultaneously, sulfation of the $\mathrm{Pd} / \mathrm{Al}_{2} \mathrm{O}_{3}$ catalyst starts by oxidation of $\mathrm{SO}_{2}$ to $\mathrm{SO}_{3}$ on the $\mathrm{PdO}$ particle. After that, $\mathrm{SO}_{3}$ over PdO can form $\mathrm{PdSO}_{4}$ or migrate to the alumina support and form $\mathrm{Al}_{2}\left(\mathrm{SO}_{4}\right)_{3}[10,12,13]$. However, sulfation is also reversible; $\mathrm{SO}_{\mathrm{x}}$ from the catalyst surface is detected to desorb already below $400{ }^{\circ} \mathrm{C}$ and the more stable support sulfates decompose above $700{ }^{\circ} \mathrm{C}$ [13]. According to Kinnunen et al. [14], sulfur hinders the mobility of oxygen and desorption of water, thus decreasing the catalyst activity for methane combustion. 
From the theoretical perspective, density functional theory (DFT) based calculations have been carried out to investigate the poisoning mechanism of $\mathrm{SO}_{\mathrm{x}}(\mathrm{x}=0-4)$ on Pd catalysts [15-18]. Using infrared reflection absorption spectroscopy (IRRAS), X-ray photoelectron spectroscopy (XPS), and DFT calculations, Luckas et al. reported the adsorption and reactivity of $\mathrm{SO}_{2}$ on $\mathrm{Pd} / \mathrm{BaO}, \mathrm{Pd}(111)$ [15], and oxygen pre-covered $\mathrm{Pd}(100)$ surfaces [16]. The energetically preferred adsorption orientation of $\mathrm{SO}_{2}$ on $\mathrm{Pd}(100)$ was the molecular plane perpendicular to the $\mathrm{Pd}$ surfaces, and the oxidation of $\mathrm{SO}_{2}$ led to $\mathrm{SO}_{3}$ and eventually to $\mathrm{SO}_{4}$ in the presence of oxygen. Based on the in situ XPS and DFT calculations, the reaction kinetics of sulfur oxidation on $\mathrm{Pd}(100)$ has also been investigated [17], and the observed main reaction intermediates where sulfates, while the amounts of $\mathrm{SO}_{2}$ and $\mathrm{SO}_{3}$ were minor. More recently, Sharma et al. [18] have studied the $\mathrm{SO}_{\mathrm{x}}(\mathrm{x}=0-4)$ oxidation on the $\operatorname{Pt}(111)$ and $\mathrm{Pd}(111)$ surfaces using DFT calculations with microkinetic modeling. They concluded that the oxidation of $\mathrm{SO}_{\mathrm{x}}$ and the formation of $\mathrm{SO}_{4}$ species are favorable on both $\mathrm{Pt}$ and $\mathrm{Pd}$, and that the $\mathrm{Pd}$ surface is more prone to sulfate formation. So far, theoretical studies have mainly focused on the interaction of $\mathrm{SO}_{\mathrm{x}}$ with metal surfaces, and investigations of sulfur species on supported Pd nanoparticles are missing.

For practical purposes, the reactivation of the sulfur-poisoned catalysts is a very interesting topic, e.g., for extending the catalyst lifetime. However, only a few scientific articles on the regeneration of sulfurpoisoned natural gas oxidation catalysts have been published. Arosio et al. [19] have studied the regeneration of the sulfur-poisoned $\mathrm{Pd} / \mathrm{Al}_{2} \mathrm{O}_{3}$ catalysts by short ( 2 minutes) $\mathrm{CH}_{4}$ pulses. Significant regeneration was observed already at $550{ }^{\circ} \mathrm{C}$ and almost complete reactivation of the catalyst was achieved at $600{ }^{\circ} \mathrm{C}$. Regeneration was associated with released $\mathrm{SO}_{2}$ due to decomposition of support sulfates promoted by $\mathrm{CH}_{4}$ activation onto the reduced metallic $\mathrm{Pd}$ surface. Thus, periodical feeding of short $\mathrm{CH}_{4}$ pulses to the NGV mufflers can regenerate the catalysts [19]. According to Kinnunen et al. [14], a sulfur-poisoned catalyst can be regenerated under low-oxygen conditions by decomposing $\mathrm{PdSO}_{4}$ to $\mathrm{PdSO}_{3}$ followed by the release of oxygen and $\mathrm{SO}_{2}$ in a wide temperature range $\left(800-1000{ }^{\circ} \mathrm{C}\right)$. However, decomposition of $\mathrm{PdSO}_{4}$ forms metallic $\mathrm{Pd}$ which is an inactive phase for methane combustion [14]. Thus, scientific studies are definitely needed to understand and improve regeneration behavior of the natural gas oxidation catalysts.

In this work, sulfur deactivation and regeneration behaviors of a $\mathrm{Pd} / \mathrm{Al}_{2} \mathrm{O}_{3}$ natural gas oxidation catalyst have been studied. Fresh and treated catalysts have been characterized by transmission electron microscopy, X-ray diffractometry, Infrared spectrometry, and their activity has been studied in catalyst performance tests. In addition, we complement the experiments by performing DFT simulations of PdO catalyst model structures on alumina support with and without interacting $\mathrm{SO}_{\mathrm{x}}$ species. 


\section{EXPERIMENTAL}

\subsection{Catalyst material}

The studied catalyst material is Pd supported on a $\gamma$-alumina washcoat on a metallic monolith. The catalyst was manufactured and designed by Dinex Ecocat Oy for lean-burn-natural-gas applications. Total palladium loading in the catalyst is $7.06 \mathrm{~g} / \mathrm{dm}^{3}$.

\subsection{Sulfur poisoning and regeneration treatments}

A sulfur with water (marked as SW) treatment was carried out at $400{ }^{\circ} \mathrm{C}$ for 5 hours in $100 \mathrm{ppm} \mathrm{SO}_{2}+10$ $\% \mathrm{H}_{2} \mathrm{O}+10 \%$ air $+\mathrm{N}_{2}$ bal. The gas hourly space velocity (GHSV) was 10,000 $\mathrm{h}^{-1}$ during the treatments. Heating to $400{ }^{\circ} \mathrm{C}$ and cooling to $25^{\circ} \mathrm{C}$ were carried out under $\mathrm{N}_{2} / 10 \%$ air. A regeneration after the SW treatment (marked as Reg. $\mathrm{CH}_{4}$ ) was carried out at $600{ }^{\circ} \mathrm{C}$ for 30 minutes in $1 \% \mathrm{CH}_{4}+\mathrm{N}_{2}$ bal. Heat treatments for the regenerated (marked as Reg. $\mathrm{CH}_{4}+$ Reg. $\mathrm{O}_{2}$ ) catalyst were carried out at $200-600{ }^{\circ} \mathrm{C}$ for 30 minutes in air.

\subsection{Characterization}

The fresh, SW-treated, and regenerated catalyst samples were studied by field emission scanning electron microscopy (FESEM, Zeiss, Crossbeam 540) together with energy dispersive spectroscopy (EDS, Oxford Instruments, $80 \mathrm{~mm}^{2} \mathrm{XMax}^{\mathrm{N}}$ silicon-drift detector) to determine the distribution and amount of sulfur. In addition, backscattered electron (BSE) images by an energy selective backscattered (EsB) detector were collected. The cross-sectional samples for FESEM studies were prepared with a conventional metallographic method: molding to resin, grinding and polishing followed by carbon-coating to avoid the sample charging in the FESEM studies. The structure of the catalysts was studied by transmission electron microscopy (TEM) and X-ray diffractometry (XRD). A TEM (Jeol JEM-2010) was used for imaging. A high resolution (scanning) TEM (HR(S)TEM, Jeol 2200FS) with two aberration correctors (CEOS GmbH) was used for high resolution STEM imaging. Bright-field (BF) and dark-field (DF) STEM images were collected. The Pd particle diameter for the fresh, SW-treated, and regenerated catalyst samples were measured from the DF STEM images. Over 50 particles were measured. The catalyst samples for all TEM studies were prepared by crushing the scraped catalyst powder between two laboratory glass slides and dispersing the crushed powder with ethanol onto a copper grid with a holey carbon film. The scraped catalyst powder was also used for XRD (PANanalytical, Empyrean with the PIXcel $^{3 \mathrm{D}}$ detector, using $\mathrm{Cu} \mathrm{K} \alpha$ radiation with a wavelength $0.15418 \mathrm{~nm}$ ) studies. Phases were identified 
from XRD patterns by using the database (PDF-4+ 2016) from the International Centre for Diffraction

Data (ICDD) and crystallite sizes were determined with the aid of the HighScore plus software based on the Scherrer equation (shape factor 0.9).

Specific surface areas, pore sizes, and pore volumes of the fresh and treated catalysts were determined using the Micrometrics ASAP 2020. Specific surface areas were measured from the $\mathrm{N}_{2}$ adsorption isotherms at $-196{ }^{\circ} \mathrm{C}(77 \mathrm{~K})$ according to the standard BET (Brunauer-Emmett-Teller) method. Pore size and pore volume distributions of catalysts were calculated from $\mathrm{N}_{2}$ desorption isotherms by the BJH (Barrett-Joyner-Halenda) method.

A Fourier transform infrared (FT-IR) spectrometer (Bruker Vertex V80) equipped with a diffuse reflectance infrared Fourier transform (DRIFT) unit and a liquid nitrogen-cooled mercury cadmium telluride (MCT) detector was utilized to find the information about the bonding of the sulfur compounds on the scraped catalyst powder. The DRIFT analyses were performed at room temperature under ambient atmosphere conditions. The background spectrum was measured using a mirror. Spectra were recorded by using a resolution of $4 \mathrm{~cm}^{-1}$.

\subsection{Catalytic testing}

Laboratory scale light-off tests were used to determine the catalyst activity of the fresh and treated catalysts. Catalytic activities were determined in lean reaction conditions using the following gas mixture: $600 \mathrm{ppm} \mathrm{CH}_{4}, 500 \mathrm{ppm} \mathrm{CO}, 10 \mathrm{vol} \% \mathrm{CO}_{2}, 12 \mathrm{vol} \% \mathrm{O}_{2}, 10 \mathrm{vol} \% \mathrm{H}_{2} \mathrm{O}$, and $\mathrm{N}_{2}$ as balance gas. The total gas flow was $1 \mathrm{dm}^{3} \cdot \mathrm{min}^{-1}$ resulting in a GHSV of $31000 \mathrm{~h}^{-1}$. The measurements were carried out at atmospheric pressure in a horizontally aligned tubular quartz reactor. The temperature of the catalyst bed was increased from room temperature up to $600{ }^{\circ} \mathrm{C}$ with a linear heating rate of $10{ }^{\circ} \mathrm{C} \cdot \mathrm{min}^{-1}$. The reactor was first heated up to $100{ }^{\circ} \mathrm{C}$ under $\mathrm{N}_{2}$ flow and then the gas mixture and water was inserted to the reactor. The catalyst was kept at steady state for $15 \mathrm{~min}$ at $600{ }^{\circ} \mathrm{C}$ and after that the reactor was cooled down to room temperature under the $\mathrm{N}_{2}$ flow. Gas flow rates were controlled by using mass flow controllers (Brooks 5280S). The gas composition was analyzed as a function of temperature by a Gasmet $^{\mathrm{TM}}$ FT-IR gas analyzer. Oxygen concentration was determined by using a paramagnetic oxygen analyzer (ABB Advanced Optima).

\subsection{Catalyst modeling}

Spin-polarized density functional theory (DFT) calculations were carried out by using the CP2K program package $[20,21]$ for all the model systems reported herein. The gradient-corrected functional of Perdew, 
Burke and Ernzerhof (PBE) [22] and the analytic pseudopotentials of Goedecker, Teter, and Hutter (GTH) [23] were employed in the calculations. Gaussian basis sets of double-zeta valence polarized (DZVP) [24] were adopted to expand the wave functions, while the cutoff energy of the auxiliary plane-wave basis for electron density was set at 600 Ry [25]. The $\Gamma$-point approximation was employed for Brillouin zone integration as the model systems are laterally large and the alumina substrate (slab) is an insulator. The DFT-D2 method was used to account for the weak van der Waals interactions [26]. Bader analysis of effective charges of atoms (based on electron density) was used to determine the charge transfer [27,28]. The activation energy barriers were calculated using the climbing-image nudged elastic band (CI-NEB) method [29].

The slab models of the alumina (100) surface used as the support were cleaved from a non-spinel $\gamma-\mathrm{Al}_{2} \mathrm{O}_{3}$ model [30]. The slab model consists of $4 \times 3$ unit cells in laterally and four layers normal to the surface (480 atoms, $22.33 \times 25.19 \AA^{2}$ ). To avoid lateral interactions of periodic catalyst replica, a larger slab with $5 \times 3$ unit cells laterally (600 atoms, $27.92 \times 25.19 \AA^{2}$ ) is also employed when more $\mathrm{SO}_{\mathrm{x}}$ species are adsorbed on the catalyst. $\mathrm{A} \mathrm{Pd}_{30}$ cluster with the square-base pyramidal structure is considered as the model structure for the Pd catalyst. The corresponding PdO catalyst cluster follows the internal geometry of bulk PdO, while the surface is sufficiently covered by oxygen atoms; the stoichiometry of the PdO model catalyst is $\mathrm{Pd}_{30} \mathrm{O}_{44}$. Note that the $\mathrm{Pd}$ sublattice is the same as for $\mathrm{Pd}_{30}$ (fcc). In this study, the catalyst of the $\mathrm{Pd}_{30} \mathrm{O}_{44}$ cluster on the $\mathrm{Al}_{2} \mathrm{O}_{3}$ substrate is considered as a representative model. A larger model catalyst would need a much larger substrate to ensure no cluster-cluster interactions. This would result in several thousands of atoms in the model structure and such DFT-simulations are not feasible in this context.

\section{RESULTS AND DISCUSSION}

\subsection{Fresh catalyst}

The cross-sectional FESEM (BSE) image of the catalyst material, Pd supported on the $\gamma-\mathrm{Al}_{2} \mathrm{O}_{3}$ washcoat, on the metallic monolith is presented in Fig. 1a. The size of the Pd particles is too small to be detected by FESEM. According to the TEM (Fig. 1b-d) and XRD (Fig. 2) results as well as $\mathrm{S}_{\mathrm{BET}}$ and BJH values (Table 1), the fresh catalyst has a nanocrystalline and porous $\gamma-\mathrm{Al}_{2} \mathrm{O}_{3}$ support with well-distributed $\mathrm{PdO}$ crystallites. The crystallite size of $\mathrm{PdO}$ in the fresh catalyst is $2 \mathrm{~nm}$ measured from the XRD pattern based on the Scherrer equation. The average diameter of the PdO particles was $1.8 \pm 0.5 \mathrm{~nm}$ measured from the DF STEM images, the histogram is presented in Fig. 3a. According to the BF STEM images (Fig. 1d), the PdO particles are single crystals and the crystallite size measured by XRD and the particle size measured from STEM images correspond to each other. The model catalyst structure of a $\mathrm{Pd}_{30} \mathrm{O}_{44}$ cluster on $\gamma$ - 
$250 \mathrm{Al}_{2} \mathrm{O}_{3}(100)$ has been optimized by DFT (Fig. 1e). Upon optimization, the $\mathrm{Pd}_{30} \mathrm{O}_{44}$ cluster exhibits a 251 hemisphere-like overall shape with the base diameter of $10.96 \AA$ and the height of $7.18 \AA$. The nearest 252 Pd-O bond length varies in the range of 1.97-2.09 $\AA$, which is comparable to the bulk value $2.02 \AA$. The 253 optimized bond distances between the cluster and the support surface vary between 1.85-2.21 $\AA$. The 254 calculated cluster adsorption energy $\left(E_{a d s}^{1}\right)$ of $\mathrm{Pd}_{30} \mathrm{O}_{44}$ is $17.46 \mathrm{eV}\left(0.185 \mathrm{eV} / \AA^{2}\right)$. Here, $E_{\text {ads }}^{1}$ is defined as 255

$$
E_{a d s}^{1}=E\left(\mathrm{Pd}_{30} \mathrm{O}_{44}\right)+E\left(\mathrm{Al}_{2} \mathrm{O}_{3}\right)-E\left(\mathrm{Pd}_{30} \mathrm{O}_{44} / \mathrm{Al}_{2} \mathrm{O}_{3}\right)
$$

257

258 where $E(X)$ is the total energy of the related system $X$. The Bader charge analysis reveals that the $\mathrm{Pd}_{30} \mathrm{O}_{44}$ 259 cluster gains $4.12 e$ of electron density in total, originating from the $\mathrm{Al}_{2} \mathrm{O}_{3}$ substrate, which results in that 260 the negatively charged catalyst is prone to interact with adsorbate molecules. The catalyst model structure 261 of a $\mathrm{Pd}_{30}$ cluster on $\gamma-\mathrm{Al}_{2} \mathrm{O}_{3}(100)$ is also optimized and shown in the Supporting Information (Fig. S1).

262 The pyramid-like geometry has a base dimension of $8.03 \times 7.98 \AA^{2}$ and height of $5.50 \AA$. The bond 263 distances between the cluster and support surface vary between 2.01-2.25 $\AA$. The calculated adsorption 264 energy of the $\mathrm{Pd}_{30}$ cluster on $\gamma-\mathrm{Al}_{2} \mathrm{O}_{3}(100)$ is $12.80 \mathrm{eV}\left(0.200 \mathrm{eV} / \AA^{2}\right)$, and according to the Bader 265 analysis, the support donates $1.62 e$ of electron density to the cluster. 

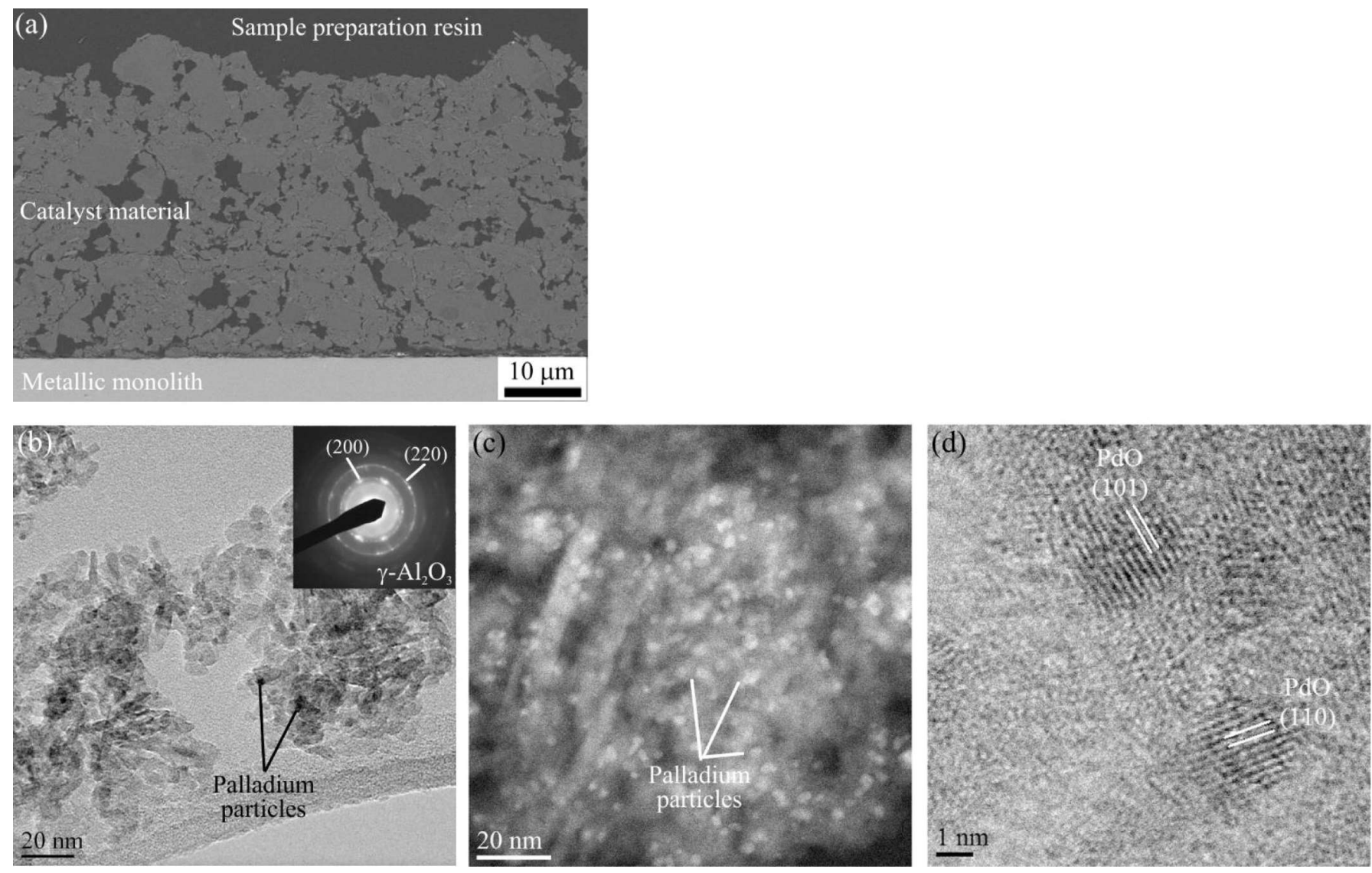

(e)
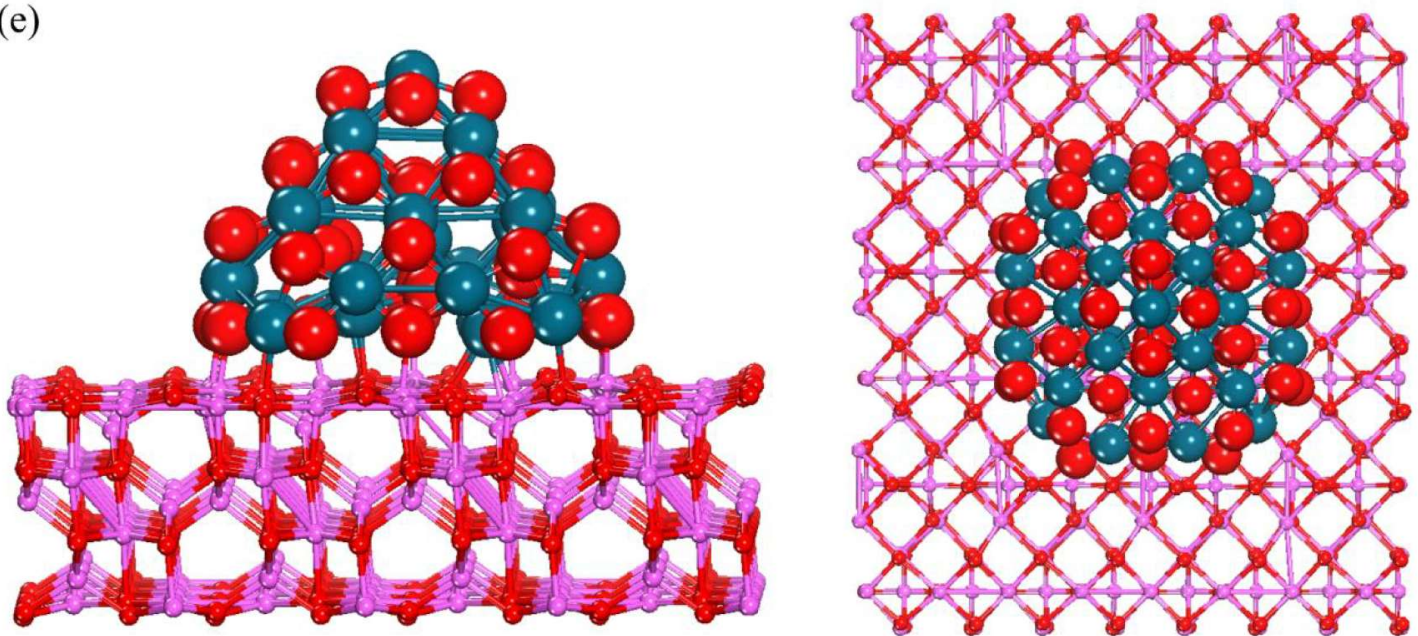

Figure 1. The fresh catalyst, (a) the cross-sectional FESEM (BSE) image showing the structure of the catalyst monolith, (b) the TEM image with the selected area electron diffraction (SAED) pattern and (c) the DF STEM image both indicating uniformly distributed palladium particles and nanocrystalline $\gamma$ $\mathrm{Al}_{2} \mathrm{O}_{3}$, (d) BF STEM image of the palladium particles wherein lattice fringes correspond to PdO, and (e) DFT-optimized model structure (side-view and top-view) of a PdO cluster catalyst on $\gamma-\mathrm{Al}_{2} \mathrm{O}_{3}$ (color key: $P d$, dark green; $O$, red; $A l$, pink). 


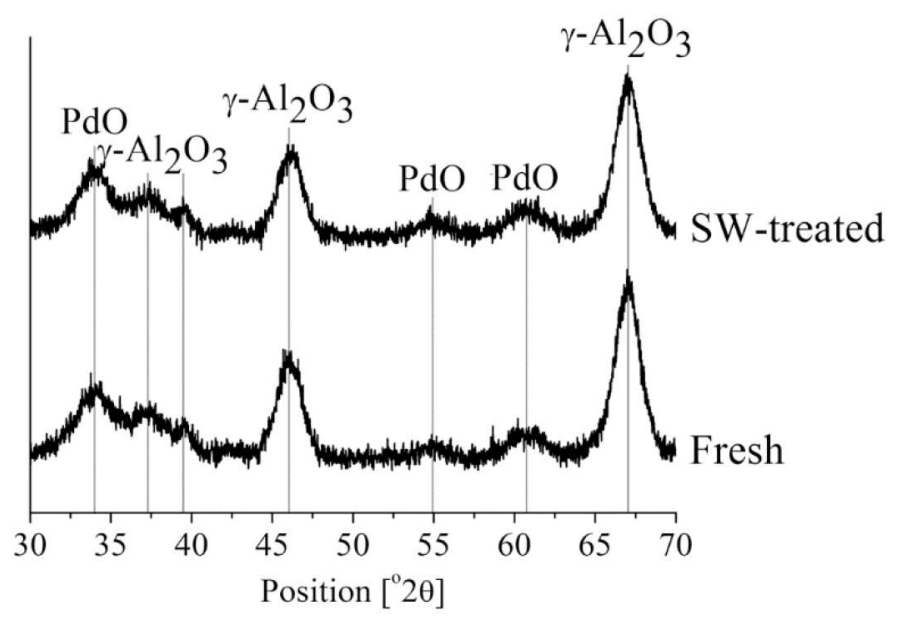

Figure 2. XRD patterns for the fresh and SW-treated catalysts.

Table 1. Specific surface area $\left(S_{B E T}\right)$, total pore volume, and average pore size of the fresh, SW-treated and regenerated (in $\mathrm{CH}_{4}$ conditions after $\mathrm{SW}$-treatment) catalysts.

\begin{tabular}{lccc}
\hline Catalyst & $\begin{array}{c}\text { Specific surface } \\
\text { area }\left[\mathrm{m}^{2} / \mathrm{g}\right]\end{array}$ & $\begin{array}{c}\text { Total pore } \\
\text { volume }\left[\mathrm{cm}^{3} / \mathrm{g}\right]\end{array}$ & $\begin{array}{c}\text { Average pore } \\
\text { size }[\mathrm{nm}]\end{array}$ \\
\hline Fresh & 180 & 0.38 & 8.5 \\
SW-treated & 175 & 0.34 & 8.0 \\
Reg. $\mathrm{CH}_{4}$ & 184 & 0.40 & 8.6 \\
\hline
\end{tabular}

(a)

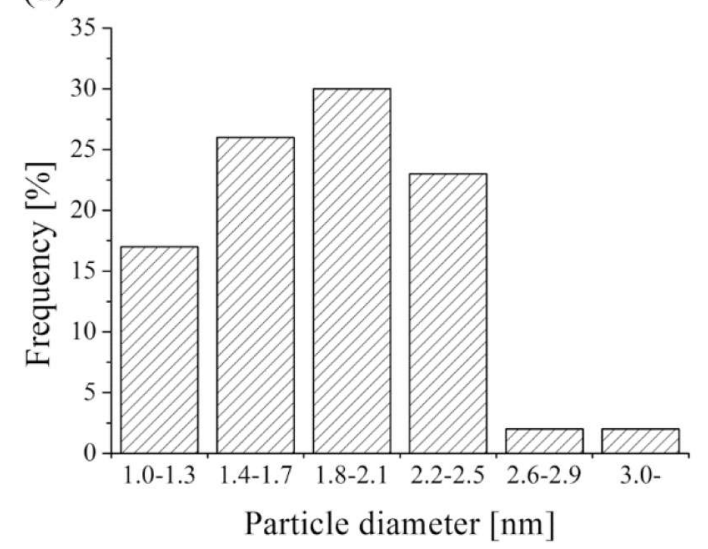

(c)

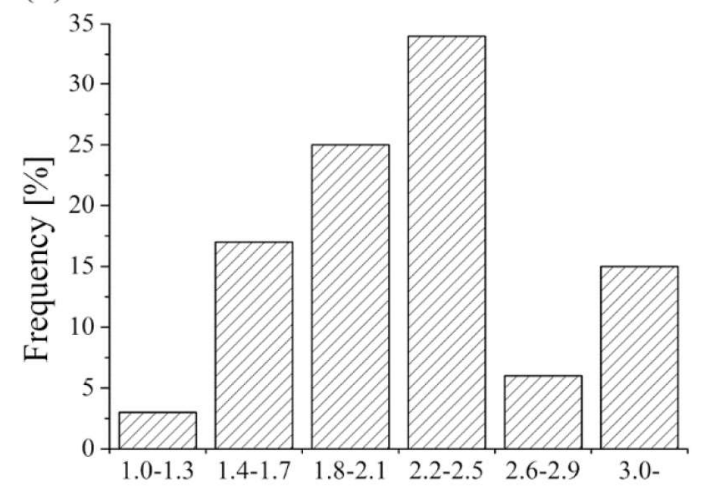

(b)

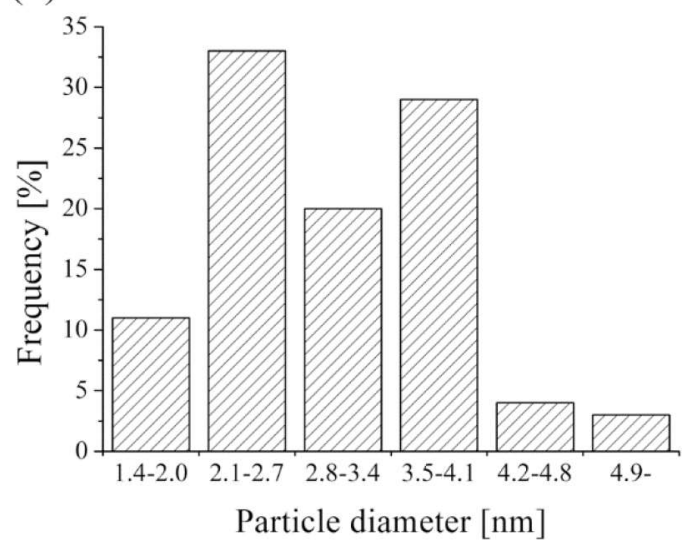
Particle diameter [nm]

Figure 3. Particle size distribution histograms of (a) the fresh catalyst, (b) the $S W$-treated catalyst, and (c) the regenerated (in $\mathrm{CH}_{4}$ conditions after $\mathrm{SW}$-treatment) catalyst. 
290 To understand the chemical nature of the $\mathrm{Pd}_{30} \mathrm{O}_{44}$ cluster adsorption on $\mathrm{Al}_{2} \mathrm{O}_{3}$, the projected density of

291 states (PDOS) of electronic structure, charge density difference (CDD) and HOMO-LUMO orbitals are

292 visualized in Fig. 4. PDOS (Fig. 4a) shows the projection of Kohn-Sham single-particle states onto

293 atomic $s$-, $p$ - and $d$-components in the catalyst and support, respectively. At the Fermi energy, PDOS has

294 significant weight on the catalyst, while the support (insulator) displays a band gap. The corresponding

295 electronic states have predominant contributions from the atomic $p$ - (oxygen) and $d$-orbitals (palladium)

296 in the $\mathrm{Pd}_{30} \mathrm{O}_{44}$ cluster. Especially, the metallic $d$-contribution at the Fermi level is a promising indicator

297 for the interaction with reactant molecules and catalytic activity. From the CDD visualization (Fig. 4b),

298 one can observe significant charge accumulation and depletion at the interface between the $\mathrm{Pd}_{30} \mathrm{O}_{44}$

299 cluster and $\mathrm{Al}_{2} \mathrm{O}_{3}$ substrate, in agreement with the observed pronounced charge transfer between the

300 cluster and substrate. In particular, the accumulated charge is distributed around the cluster perimeter.

301 Furthermore, the HOMO and LUMO orbital distributions (Fig. 4b) show that both states are mainly

302 delocalized around the $\mathrm{Pd}_{30} \mathrm{O}_{44}$ cluster (supporting the PDOS results in Fig. 4a), while there is

303 insignificant electron distribution around the $\mathrm{Al}_{2} \mathrm{O}_{3}$ support. Similar observations were made for the non-

304 oxidized $\mathrm{Pd}_{30}$ cluster catalyst on $\mathrm{Al}_{2} \mathrm{O}_{3}$, and the corresponding PDOS, CDD visualization and HOMO-

305 LUMO orbitals are given in Fig. S2. 

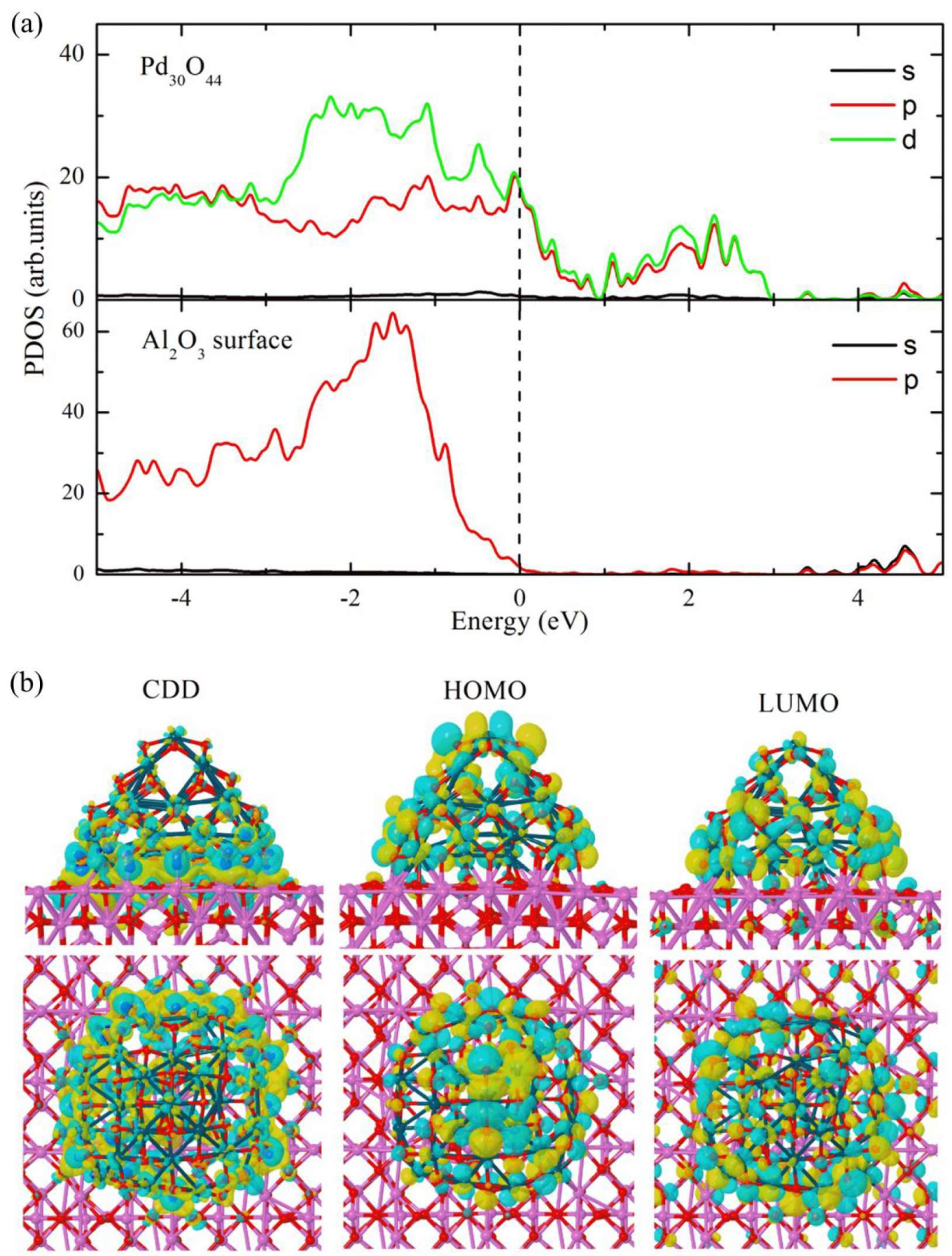

Figure 4. Calculated electronic properties of the $\mathrm{Pd}_{30} \mathrm{O}_{44} / \mathrm{Al}_{2} \mathrm{O}_{3}(100)$ system: (a) Projected density of states (PDOS) onto atomic $s$-, $p$ - and d-orbitals in the cluster and support, respectively. The vertical dashed line indicates the Fermi level, where the main weight can be associated with $O-2 p$ and $P d-4 d$. (b) Side and top views of charge density difference (CDD) and HOMO/LUMO orbitals. For CDD, the yellow and cyan colors represent charge accumulation and depletion, respectively, while the net accumulation in the cluster is 4.12 e. For HOMO/LUMO, the different colors mark different nodes (signs) of the corresponding wavefunction. The isosurface values are $\pm 0.002 \mathrm{e}_{\mathrm{a} 0^{3}}$ for CDD and \pm 0.01 ela ${ }^{3}$ for HOMO and LUMO. 


\subsection{SW-treated catalyst}

Based on the XRD (Fig. 2) and TEM (Fig. 5) results, the morphology of the $\gamma-\mathrm{Al}_{2} \mathrm{O}_{3}$ support after the $\mathrm{SW}$-treatment is similar to the fresh catalyst. In addition, palladium particles were detected in the PdO form after the SW-treatment (Figs. 2 and 5c), similar to the fresh catalyst. However, the PdO crystallite size in the SW-treated catalyst is $4 \mathrm{~nm}$ as measured from the XRD pattern (Fig. 2) by the Scherrer equation while it was $2 \mathrm{~nm}$ in the fresh catalyst. The average diameter of the PdO particles was $3.0 \pm 0.8$ $\mathrm{nm}$ measured from the DF STEM images, the histogram is presented in Fig. 3b. According to the BF STEM images (Fig. 5c), the PdO particles are single crystals. There is a slight fluctuation between the measurements by XRD and from the STEM images likely due to a small sampling of the particles in the measurement from the STEM images. However according to both measurements, a slight crystallite growth of $\mathrm{PdO}$ occurred during the SW-treatment. Lee et al. [31] have proposed that $\mathrm{SO}_{2}$-induced sintering of $\mathrm{Pt}$ particles in the $\mathrm{Pt} / \mathrm{Al}_{2} \mathrm{O}_{3}$ catalyst results from the reaction of $\mathrm{SO}_{2}$ with oxygen at the Pt-O$\mathrm{Al}$ interface weakening the $\mathrm{Pt}-\mathrm{O}$ interaction and promoting the migration and sintering of $\mathrm{Pt}$ particles. A similar mechanism may cause a slight sintering of PdO crystallites in the studied catalyst. According to our earlier study [32], a slight sulfur-induced growth of the PtPd particles in the $\mathrm{PtPd} / \mathrm{Al}_{2} \mathrm{O}_{3}$ catalyst was observed and a small amount of bulk aluminum sulfate species was detected near the PtPd particles. In the studied catalyst, the micro-scale distribution of sulfur studied by FESEM-EDS was observed to be uniform and the amount of sulfur was $\sim 2 \mathrm{wt} \%$. According to the DRIFT spectra (Fig. 6), at 1160-1200 $\mathrm{cm}^{-1}$ the formation of bulk $\mathrm{Al}_{2}\left(\mathrm{SO}_{4}\right)_{3}$ on the $\mathrm{SW}$-treated catalyst was detected [33,34]. However, the band at $\sim 1300 \mathrm{~cm}^{-1}$ indicating surface $\mathrm{Al}_{2}\left(\mathrm{SO}_{4}\right)_{3}$ [33] was not observed. Also, the band at $\sim 1435 \mathrm{~cm}^{-1}$ corresponding to $v(\mathrm{~S}=\mathrm{O})$ of $\mathrm{Pd}-\mathrm{SO}_{4}$ species [35] was not found. It can be assumed that the bands at 1035 and $1639 \mathrm{~cm}^{-1}$ are material originated ones as they exist in all spectra and their intensities and band positions were not changed or affected by treatments. It has been reported that the sulfur poisoning of the $\mathrm{Pd} / \mathrm{Al}_{2} \mathrm{O}_{3}$ catalyst starts by oxidation of $\mathrm{SO}_{2}$ to $\mathrm{SO}_{3}$ on the $\mathrm{PdO}$ particle followed by the formation of $\mathrm{PdSO}_{4}$ and/or $\mathrm{Al}_{2}\left(\mathrm{SO}_{4}\right)_{3}[10,12,13]$. Based on these results, it can be deduced that sulfur migrates to the $\mathrm{Al}_{2} \mathrm{O}_{3}$-based support forming bulk $\mathrm{Al}_{2}\left(\mathrm{SO}_{4}\right)_{3}$. Sulfur compounds likely block a part of the pore openings resulting in a slightly decreased specific surface area, total pore volume, and average pore size during the SW-treatment (Table 1). 

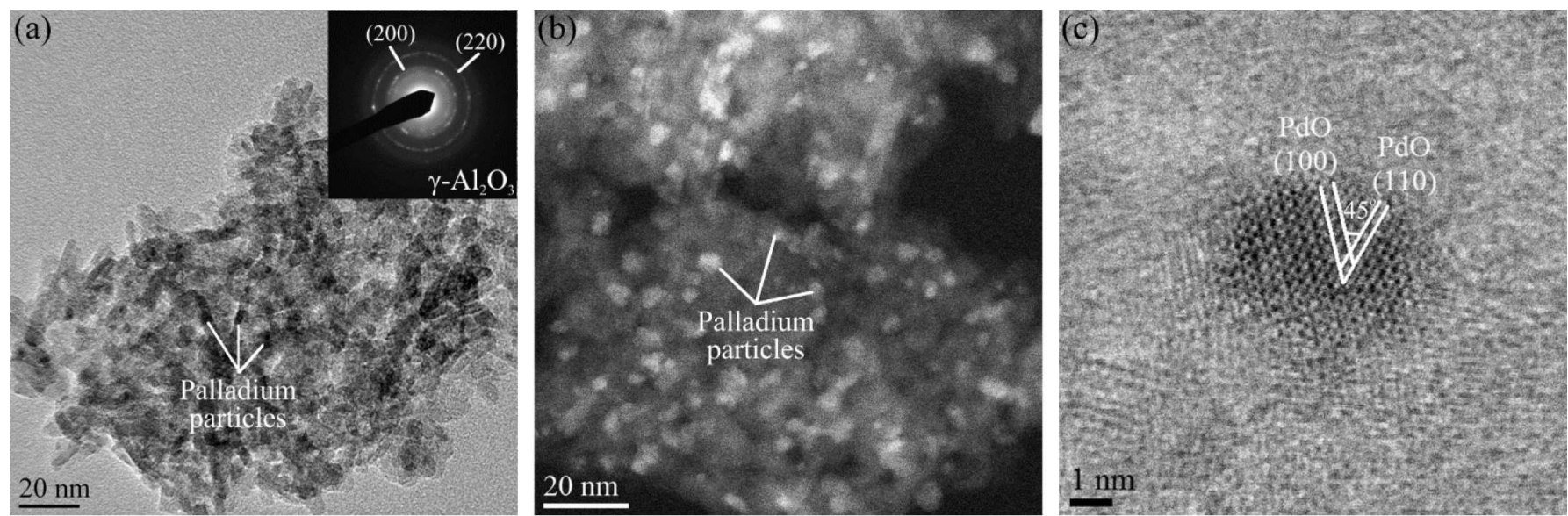

Figure 5. The SW-treated catalyst, (a) the TEM image with the SAED pattern and (b) the DF STEM image both indicating uniformly distributed palladium particles and nanocrystalline $\gamma-\mathrm{Al}_{2} \mathrm{O}_{3}$ and (c) the BF STEM image of the palladium particle wherein lattice fringes correspond to PdO.

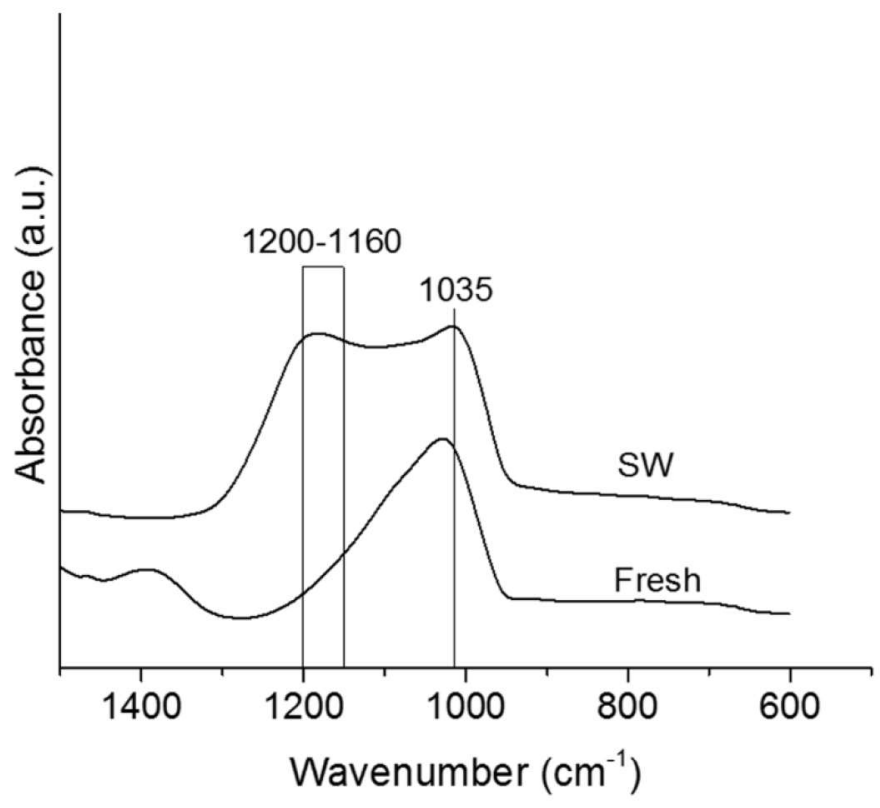

Figure 6. DRIFT spectra for the fresh and $S W$-treated catalysts.

Since the sulfur oxides $\left(\mathrm{SO}_{\mathrm{x}}\right)$ will modify the catalyst surface chemistry and prevent access of reactants to the surface, it is necessary to identify and get detailed knowledge on the adsorption properties of the $\mathrm{SO}_{\mathrm{x}}$ species on the $\mathrm{Pd}_{30} \mathrm{O}_{44} / \mathrm{Al}_{2} \mathrm{O}_{3}$ catalyst and estimate the saturation adsorption of $\mathrm{SO}_{\mathrm{x}}$. The optimized most stable structures of a single $\mathrm{SO}_{\mathrm{x}}$ adsorption on the $\mathrm{Pd}_{30} \mathrm{O}_{44} / \mathrm{Al}_{2} \mathrm{O}_{3}$ catalyst are shown in Fig. S3. The calculated adsorption energy $\left(E_{\text {ads }}^{S O X}\right)$, net charge and geometric parameters are summarized in Table S1. According to DFT optimizations, the adsorbed $\mathrm{SO}_{x}$ forms the following configurations: $\mathrm{SO}_{2}$ for $\mathrm{S}, \mathrm{SO}_{3}$ for $\mathrm{SO}$, and $\mathrm{SO}_{4}$ for $\mathrm{SO}_{2}$ and $\mathrm{SO}_{3}$, respectively, through binding more $\mathrm{O}$ atoms from the $\mathrm{PdO}$ cluster surface. This is in agreement with the experimental observations, where stable configurations of $\mathrm{SO}_{2}$, and then $\mathrm{SO}_{3}$ and $\mathrm{SO}_{4}$ have been observed upon $\mathrm{SO}_{x}$ adsorption on Pd catalysts in the presence of oxygen [15-17]. The $\mathrm{SO}_{\mathrm{x}}(\mathrm{x}=0-4)$ species show a strong interaction with the catalyst due to covalent binding where the adsorbed SO has the largest adsorption energy. Bader charge analysis shows that PdO donates 

$374\left(E_{\text {ads }}^{(S O 3) n}\right)$ was calculated as:

electron density towards $\mathrm{SO}_{\mathrm{x}}$. Overall, the amount of charge transfer increases almost linearly with $x$, and an adsorbed $\mathrm{SO}_{4}$ gains $0.72 e$ additional charge from $\mathrm{PdO}$.

As a representative case, the saturation adsorption of $\mathrm{SO}_{3}$ on $\mathrm{Pd}_{30} \mathrm{O}_{44} / \mathrm{Al}_{2} \mathrm{O}_{3}$ has been carefully evaluated by adding $\mathrm{SO}_{3}$ molecules one-by-one on the catalyst. The adsorption energy of the $n$-th $\mathrm{SO}_{3}$ molecule

$$
E_{a d s}^{(S O 3) n}=E\left(S_{3}\right)+E(n-1)-E(n)
$$

where $E\left(\mathrm{SO}_{3}\right), E(n-1)$ and $E(n)$ are the total energies of the $\mathrm{SO}_{3}$ molecule and systems with $(n-1)$ and $n$ adsorbed $\mathrm{SO}_{3}$. The calculated $E_{a d s}^{(\mathrm{SO}) n}$ as a function of $\mathrm{SO}_{3}$ number $n$ is plotted in Fig. 7a. The $E_{a d s}^{(\mathrm{SO}) n}$ varies in the range of $0.50(n=5)$ to $2.22 \mathrm{eV}(\mathrm{n}=15)$ for $\mathrm{n}=1-16$, and then goes to a negative value at $\mathrm{n}=17$ (Fig. 7a). Thus, the saturation adsorption of $\left(\mathrm{SO}_{3}\right)_{\mathrm{n}}$ on $\mathrm{Pd}_{30} \mathrm{O}_{44} / \mathrm{Al}_{2} \mathrm{O}_{3}$ is reached at $n=16$, corresponding to a case where $\mathrm{Pd}_{30} \mathrm{O}_{44}$ is encapsulated by $\mathrm{SO}_{\mathrm{x}}$ (Fig. 7c). Despite the forming S-O bonds, the catalyst structure retains the original internal Pd-O geometry. It was observed also by STEM that the structure of the PdO particles is similar in the fresh and SW-treated catalysts (Figs. 1d and 5c). All adsorbed $\mathrm{SO}_{3}$ molecules form $\mathrm{PdSO}_{4}$ complexes by binding $\mathrm{Pd}$ and $\mathrm{O}$ atoms on the $\mathrm{Pd}_{30} \mathrm{O}_{44}$ surface, while the $\mathrm{SO}_{3}$ at the interface also bind $\mathrm{Al}$ atoms in the $\mathrm{Al}_{2} \mathrm{O}_{3}$ support. The average adsorption energy of a $\mathrm{SO}_{3}$ molecule is $1.01 \mathrm{eV}$. The PDOS of the $\mathrm{SO}_{3}$ encapsulated $(n=16)$ case is displayed in Fig. $7 \mathrm{~b}$. Although there is still considerable weight, the features near the Fermi level have changed in comparison with the naked $\mathrm{Pd}_{30} \mathrm{O}_{44}$ cluster due to the covalent bonding between sulfur and oxygen. Bader charge analysis shows that the $\mathrm{PdO}$ cluster donates $4.69 e$ of electron density to the encapsulating layer, leaving the cluster itself slightly negatively charged followed by reduction in chemical activity (see below). 
(a)

(c) Pd catalysts than oxygen.

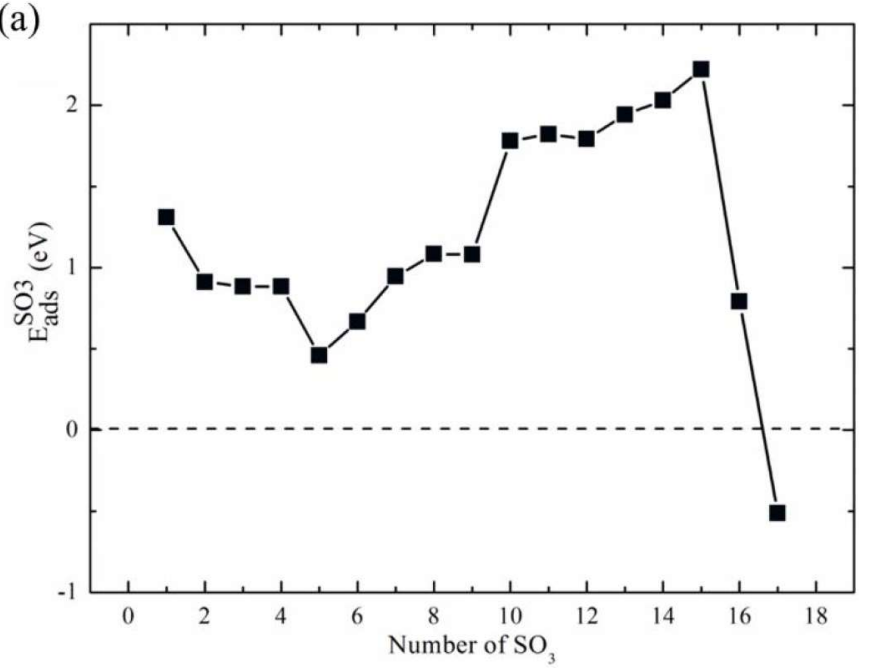

(b)
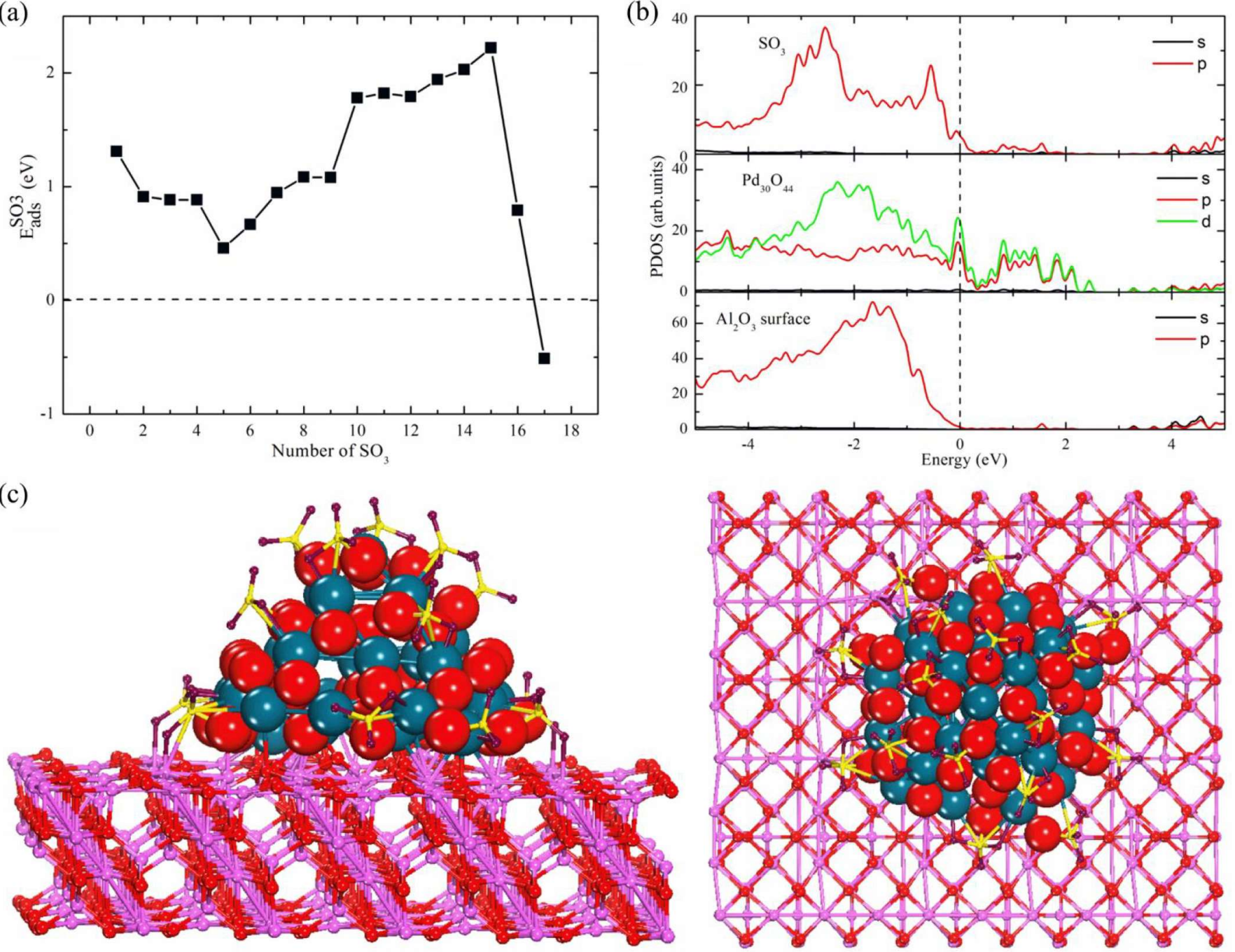

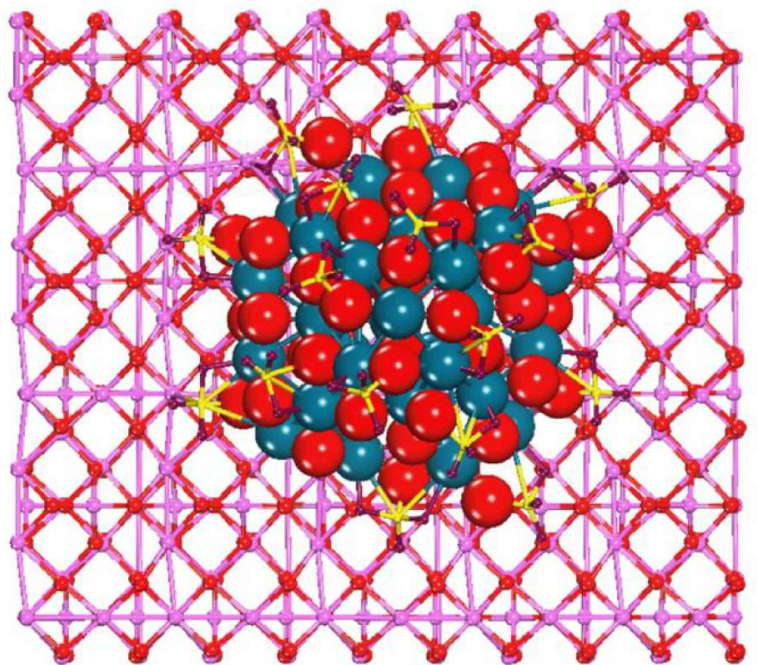

Figure 7. (a) $\mathrm{SO}_{3}$ adsorption energy ( $E_{\text {ads }}^{(\mathrm{SO}) n}$ ) as a function of $\mathrm{SO}_{3}$ number $n$ for multiple $\mathrm{SO}_{3}$ adsorbed on $\mathrm{Pd}_{30} \mathrm{O}_{44} / \mathrm{Al}_{2} \mathrm{O}_{3}(100)$. (b) Projected density of states (PDOS) onto atomic $s$-, $p$ - and $d$-orbitals for $\left(\mathrm{SO}_{3}\right)_{16}$ adsorbed $\mathrm{Pd}_{30} \mathrm{O}_{44} / \mathrm{Al}_{2} \mathrm{O}_{3}(100)$. The vertical line indicates the Fermi level. (c) Side and top view of the optimized structure of $\left(\mathrm{SO}_{3}\right)_{16}$ adsorbed $\mathrm{Pd}_{30} \mathrm{O}_{44} / \mathrm{Al}_{2} \mathrm{O}_{3}(100)$. The Pd-sublattice remains intact.

Experimentally, sulfur composition has been observed also within the interior of the PdO catalysts upon $\mathrm{SO}_{\mathrm{x}}$ exposure. Correspondingly, we have probed the substitution of $\mathrm{O}$ atoms by $\mathrm{S}$ atoms inside the $\mathrm{Pd}_{30} \mathrm{O}_{44} / \mathrm{Al}_{2} \mathrm{O}_{3}$ catalyst. At first, the diffusion of $\mathrm{O}$ and $\mathrm{S}$ atoms from the surface towards the interior of the $\mathrm{Pd}_{30} / \mathrm{Al}_{2} \mathrm{O}_{3}$ catalyst has been simulated. The optimized structures and energy diagrams along the diffusion paths are given in Fig. S5 and S6. The diffusion barriers for sulfur are lower, 0.86 (first transition state, TS1) and $1.02 \mathrm{eV}$ (second, transition state, TS2), than those for oxygen, 0.94 (TS1) and $1.17 \mathrm{eV}$ (TS2). Based on these results, we estimate that atomic sulfur diffuses more readily inside fresh

For the substitution of $\mathrm{O}$ atoms in the $\mathrm{Pd}_{30} \mathrm{O}_{44}$ cluster, the optimal sulfur substitution site was found at the bottom layer of $\mathrm{Pd}_{30} \mathrm{O}_{44}$, where the substituted $\mathrm{S}$ atom is tetrahedrally surrounded by four $\mathrm{Pd}$ atoms with the S-Pd bond lengths of $2.4 \AA$ (compare with that of $2.1 \AA$ for O-Pd). The S substitution is energetically 
favorable by $0.67 \mathrm{eV}$. Here, the substitution energy was calculated as the difference between the total energies of individual systems before substitution (free $\mathrm{S}$ atom and $\mathrm{PdO}$ catalyst) and those of after substitution (free $\mathrm{O}$ atom and $\mathrm{S}$-substituted $\mathrm{PdO}$ catalyst). The number of substituting $\mathrm{S}$ atoms has also been varied between 2 and 6 in the bottom layer of the PdO cluster. The calculated substitution energies are 0.61 and $0.51 \mathrm{eV} / \mathrm{S}$, respectively, while PDOS does not show significant changes (Fig. S7). The longer Pd-S bond distances cause strain inside the cluster and one cannot increase the S-content further without breaking the internal geometry of the cluster. Overall, the direct substitution by $\mathrm{S}$ inside the cluster does not give indications of reduced catalytic activity, while there are geometric limitations in terms of strain.

\subsection{Regenerated catalysts}

Based on the XRD (Fig. 8a) and TEM (Fig. 9a) studies, the morphology of the $\gamma-\mathrm{Al}_{2} \mathrm{O}_{3}$ support in the regenerated (in $\mathrm{CH}_{4}$ conditions after $\mathrm{SW}$-treatment) catalyst is similar to the fresh and $\mathrm{SW}$-treated catalysts. However, during the regeneration treatment, $\mathrm{PdO}$ particles have partly reduced to metallic $\mathrm{Pd}$ (Figs. 8a and 9c). The crystallite size of Pd cannot be determined based on the XRD pattern due to the overlapping of the $\mathrm{Pd}$ and $\gamma-\mathrm{Al}_{2} \mathrm{O}_{3}$ peaks. The average diameter of the Pd particles was $2.3 \pm 0.7 \mathrm{~nm}$ measured from the DF STEM images thus the size of Pd particles is similar to the size of the PdO particles in the fresh (Fig. 1) and SW-treated (Fig. 5) catalysts. According to the DF STEM images (Fig. 9b), the Pd particles are uniformly distributed and based on the BF STEM images (Fig. 9c), the particles are single crystals. Based on the literature, methane can reduce $\mathrm{PdO}$ in the $\mathrm{Pd} / \mathrm{Al}_{2} \mathrm{O}_{3}$ catalyst already at 280-290 ${ }^{\circ} \mathrm{C}$ [8]. In our study after the regeneration treatment in $\mathrm{CH}_{4}$ conditions, a small amount of sulfur $(\sim 1 \mathrm{wt} \%)$ was still detected by FESEM-EDS uniformly in the catalyst layer. In the DRIFT spectrum of the regenerated catalyst (Fig. 8b), a band at $1194 \mathrm{~cm}^{-1}$ was detected indicating bulk $\mathrm{Al}_{2}\left(\mathrm{SO}_{4}\right)_{3}[33,34]$. In addition, a band at $1468 \mathrm{~cm}^{-1}$ assigned to sulfur species on the palladium particles [36,37] was detected, although this was absent after the SW treatment (Fig. 8b). This could be due to $\mathrm{SO}_{3}$ spilling from the support onto $\mathrm{PdO}$ forming $\mathrm{PdSO}_{4}$ [10]. Gélin et al. [38] have suggested that when sulfate species are only partly removed from the catalyst, sulfates can migrate back and forth between $\mathrm{PdO}$ and the $\mathrm{Al}_{2} \mathrm{O}_{3}$ support preventing the complete regeneration until there is no sulfur species in the neighborhood of PdO particles. In addition, the decomposition of $\mathrm{PdSO}_{4}$ to $\mathrm{PdSO}_{3}$ releases oxygen and $\mathrm{SO}_{2}$ and forms metallic $\mathrm{Pd}$ [14]. Partial reduction of $\mathrm{PdO}$ to $\mathrm{Pd}$ was observed by XRD (Fig. 8a) during the regeneration treatment with methane in this study. The $\mathrm{S}_{\mathrm{BET}}$ and BJH values after the regeneration recovered to the level of the fresh catalyst (Table 1) most probably indicating the removal of bulk $\mathrm{Al}_{2}\left(\mathrm{SO}_{4}\right)_{3}$ from pore openings. 
(a)

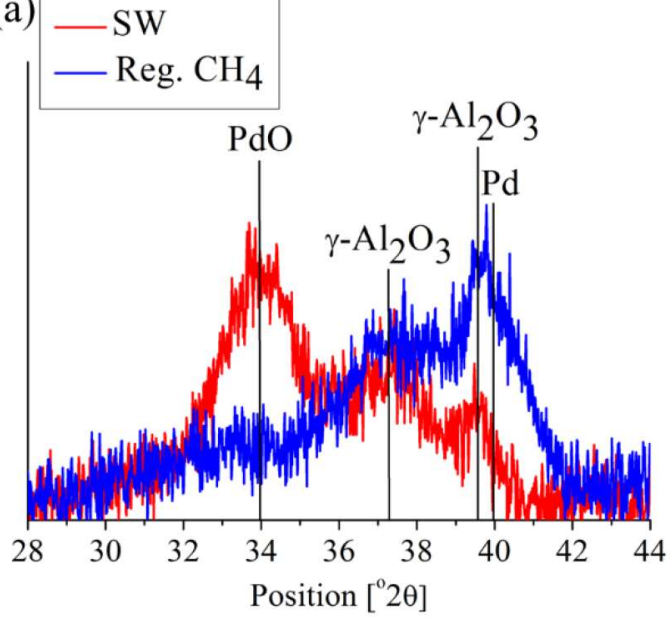

(b)

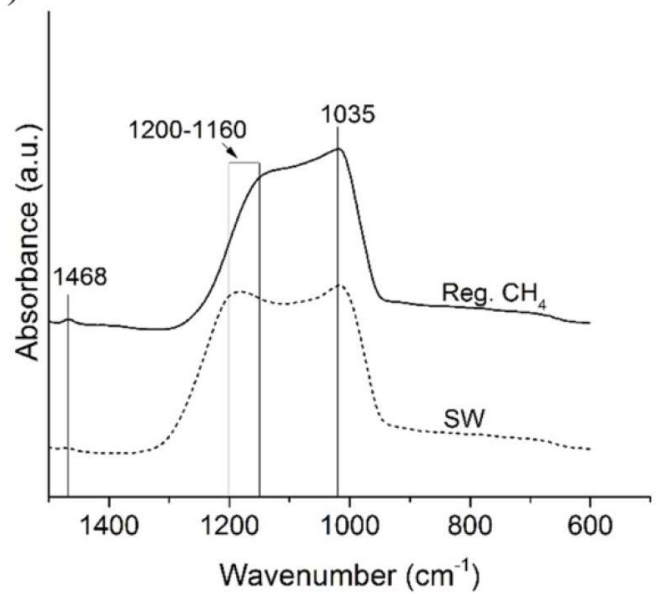

Figure 8. (a) XRD patterns and (b) DRIFT spectra for the catalyst after the regeneration treatment in $\mathrm{CH}_{4}$ conditions. The $S W$-treated catalyst is presented for comparison.
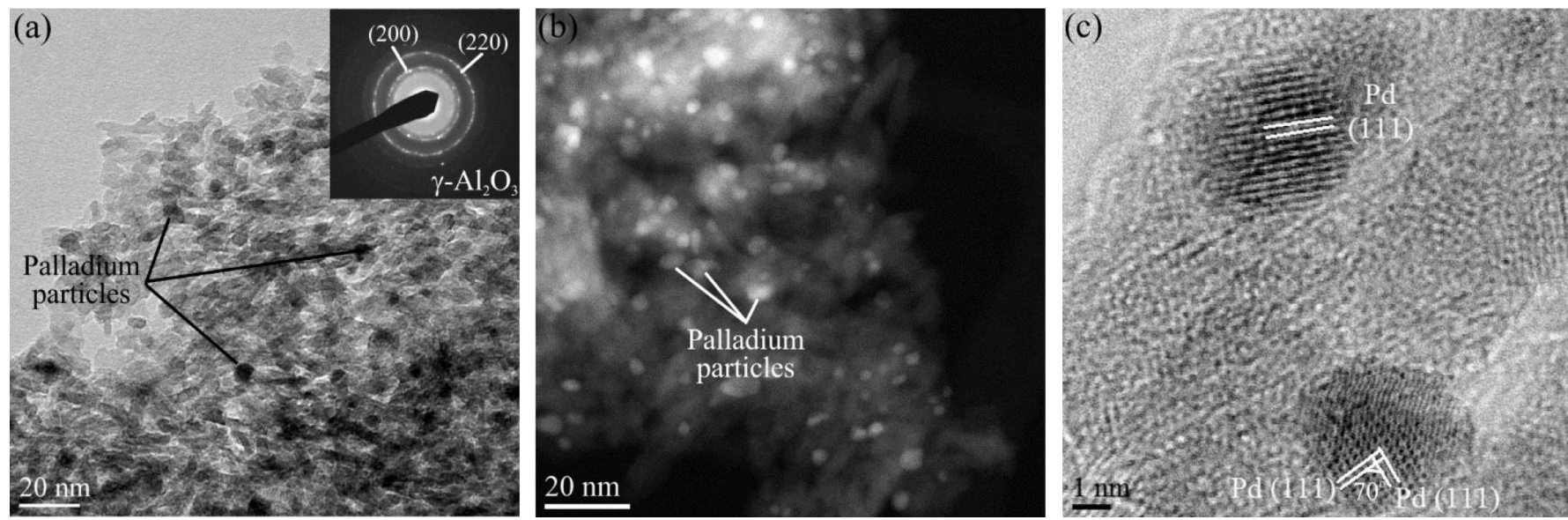

Figure 9. The regenerated (in $\mathrm{CH}_{4}$ conditions after $\mathrm{SW}$-treatment) catalyst, (a) the TEM image with the SAED pattern and (b) the DF STEM image both indicating uniformly distributed palladium particles and nanocrystalline $\gamma-\mathrm{Al}_{2} \mathrm{O}_{3}$ and (c) BF STEM image of the palladium particles wherein lattice fringes correspond to metallic $P d$.

To study how Pd can be reoxidized to PdO after the regeneration treatment and to study the effect of Pd vs. $\mathrm{PdO}$ on the catalyst performance, the regenerated (in $\mathrm{CH}_{4}$ conditions) catalyst was further regenerated in $\mathrm{O}_{2}$ conditions at various temperatures. According to the XRD results (Fig. 10a), reoxidation started at $300{ }^{\circ} \mathrm{C}$ (PdO peaks started to grow) and the XRD pattern of the catalyst treated at $350{ }^{\circ} \mathrm{C}$ was similar to the XRD pattern of the fresh catalyst indicating complete oxidation. When Pd reoxidizes to PdO, the color of the catalyst changes from black back to light brown similar to the fresh catalyst (Fig. 10a). The DRIFT measurements of the further regenerated (in $\mathrm{O}_{2}$ conditions) catalysts (Fig. 10b) still show the presence of bulk $\mathrm{Al}_{2}\left(\mathrm{SO}_{4}\right)_{3}$ (bands at $1160-1200 \mathrm{~cm}^{-1}$ ) at all studied temperatures $\left(200-600{ }^{\circ} \mathrm{C}\right)$. Also, the FESEM-EDS studies indicated a small amount ( $\sim \mathrm{wt} \%)$ of sulfur uniformly distributed in the catalyst. A band at $1468 \mathrm{~cm}^{-1}$ (Fig. 10b), indicating sulfur species on the palladium particles [36,37], disappears at higher temperatures. The unassigned band at $1560 \mathrm{~cm}^{-1}$ was found to follow the same trend. The most probable explanation is that sulfur species decompose in the neighborhood of the palladium 
particles more efficiently at higher temperatures and thus, after the 30 minutes treatment at higher temperatures only bulk $\mathrm{Al}_{2}\left(\mathrm{SO}_{4}\right)_{3}$ exists. The gained results are in agreement with the results by Arosio et al. [19].

(a)

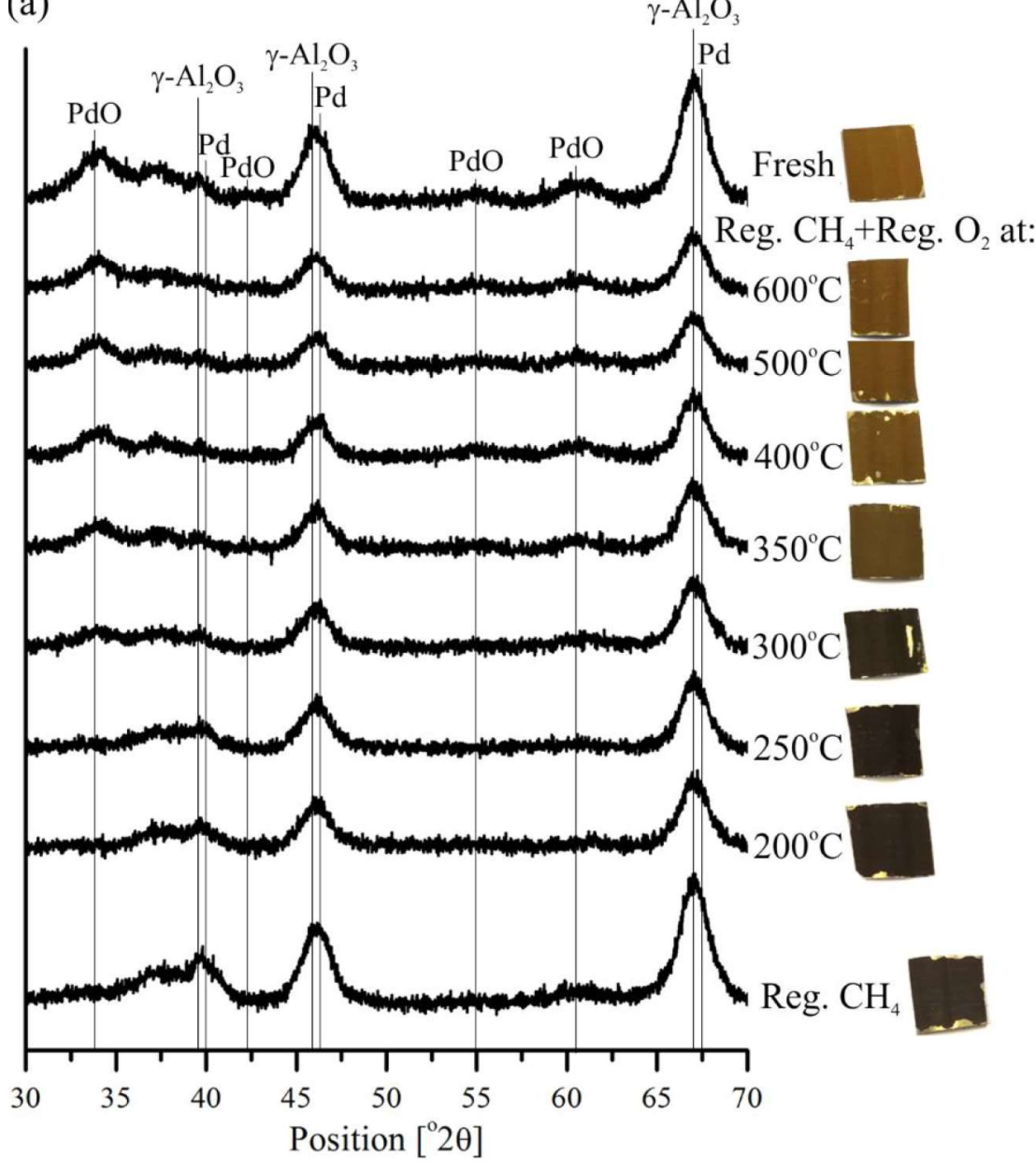

(b)

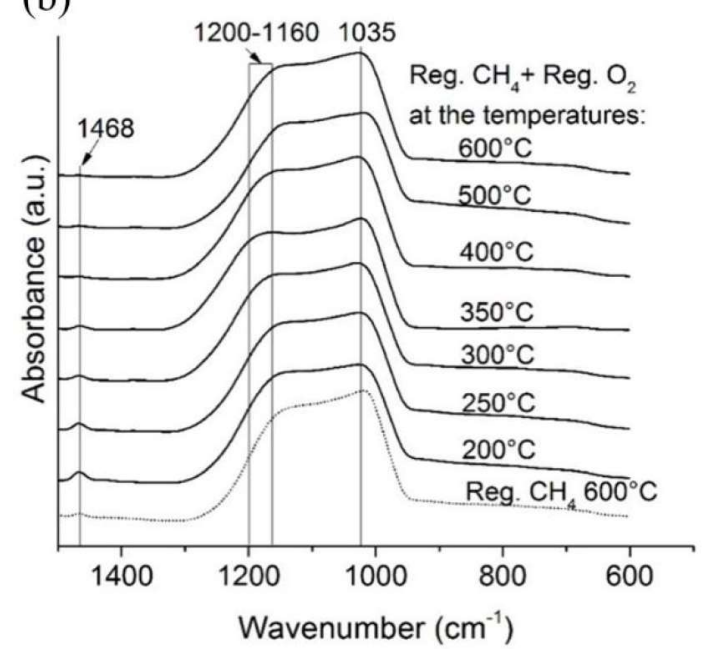

Figure 10. (a) XRD patterns for the catalysts after the regeneration treatment in $\mathrm{CH}_{4}$ conditions followed by the regeneration treatment in $\mathrm{O}_{2}$ conditions at 200-600 ${ }^{\circ} \mathrm{C}$. The XRD patterns for the catalyst after regeneration treatment in $\mathrm{CH}_{4}$ conditions and the fresh catalyst are presented for comparison. In addition, the pictures of the corresponding catalyst monoliths are presented showing their color. (b) DRIFT spectra for the catalysts after the regeneration treatment in $\mathrm{CH}_{4}$ conditions followed by the regeneration treatment in $\mathrm{O}_{2}$ conditions at $200-600{ }^{\circ} \mathrm{C}$. 


\subsection{Catalyst performance in $\mathrm{CH}_{4}$ oxidation}

The performance of the catalysts in $\mathrm{CH}_{4}$ oxidation was studied theoretically and experimentally. The first C-H bond activation upon $\mathrm{CH}_{4}$ oxidation $\left(\mathrm{CH}_{4}+\mathrm{O}^{*}+\mathrm{O}^{*} \rightarrow \mathrm{CH}_{3} \mathrm{O}^{*}+\mathrm{OH}^{*}\right)$ was simulated on the $\mathrm{Pd}_{30} \mathrm{O}_{44} / \mathrm{Al}_{2} \mathrm{O}_{3}$ system since the first $\mathrm{C}-\mathrm{H}$ bond activation is the crucial step for the rest $\mathrm{C}$ - $\mathrm{H}$ bonds breaking in $\mathrm{CH}_{4}$ [39]. The optimal adsorption site of the $\mathrm{CH}_{4}$ molecule was mapped by placing $\mathrm{CH}_{4}$ on different sites on the $\mathrm{Pd}_{30} \mathrm{O}_{44}$ surface. Based on the preferable $\mathrm{CH}_{4}$ adsorption site, a co-adsorption configuration of $\mathrm{CH}_{3}+\mathrm{H}$ was also optimized. Here, the adsorption energy $\left(E_{\text {ads }}^{2}\right)$ was calculated as

$$
E_{\text {ads }}^{2}=E(\text { adsorbate })+E\left(\mathrm{Pd}_{30} \mathrm{O}_{44} / \mathrm{Al}_{2} \mathrm{O}_{3}\right)-E\left(\text { adsorbate }+\mathrm{Pd}_{30} \mathrm{O}_{44} / \mathrm{Al}_{2} \mathrm{O}_{3}\right)
$$

where $\mathrm{E}(\mathrm{X})$ is the total energy of the corresponding system $\mathrm{X}$. Figure 11 displays the structures of the initial state (IS), transition state (TS), intermediate state (IM), and final state (FS), and the energy diagram of reaction pathway for the first $\mathrm{C}-\mathrm{H}$ bond activation in $\mathrm{CH}_{4}$ oxidation over $\mathrm{O}^{*}-\mathrm{O}^{*}$ site pairs (labeled with $\mathrm{O}_{1}-\mathrm{O}_{2}$ ), respectively. At IS, the $\mathrm{CH}_{4}$ molecule binds weakly on the $\mathrm{Pd}_{30} \mathrm{O}_{44}$ surface with $E_{\text {ads }}^{2}=0.40$ $\mathrm{eV}$ and the C-Pd distance of $3.25 \AA$. Note that the binding site is at the cluster-surface perimeter which is also the region of most donated charge (Fig. 4). In the first transition state (TS1), the C-H bond length increases from $1.10 \AA\left(\mathrm{CH}_{4}\right.$ in gas phase) to $1.33 \AA$ and binds to the $\mathrm{Pd}$ and $\mathrm{O}^{*}$ (labeled $\left.\mathrm{O}_{1}\right)$ atoms with the C-Pd, H-Pd and H-O* bond lengths of 2.25, 1.86 and $1.31 \AA$, respectively. The corresponding activation barrier is $0.66 \mathrm{eV}$, consistent with the scaling of $0.76 \pm 0.11 \mathrm{eV}$ computed by the methane $\mathrm{C}-\mathrm{H}$ bond activation equation in Ref. [40]. The elongated C-H bond in TS1 cleaves as the reaction progresses leading to the formation of C-Pd and $\mathrm{H}-\mathrm{O} *$ bonds at IM. After that, the $\mathrm{CH}_{3} \mathrm{O}^{*}+\mathrm{HO}^{*}$ fragments are produced at FS after crossing over the second transition state (TS2) with a reaction barrier of $0.43 \mathrm{eV}$ along the reaction path. For reference, the first $\mathrm{C}-\mathrm{H}$ bond activation upon $\mathrm{CH}_{4}$ dissociation over a pyramidal $\mathrm{Pd}_{30}$ cluster supported on $\gamma-\mathrm{Al}_{2} \mathrm{O}_{3}(100)$ surface was also simulated (Fig. S4), and the resulting activation barrier $(0.88 \mathrm{eV})$ is noticeably higher than that of the $\mathrm{PdO}$ catalyst. This is agreement with the general knowledge that $\mathrm{PdO}$ is more active in $\mathrm{CH}_{4}$ oxidation than $\mathrm{Pd}$. Similar transition states have also been observed for $\mathrm{CH}_{4}$ activation over $\mathrm{PdO}(101)$ and $\mathrm{Pd}(111)$ surfaces with the calculated activation barriers of 0.64 and $0.76 \mathrm{eV}$, respectively [41]. 
(a)

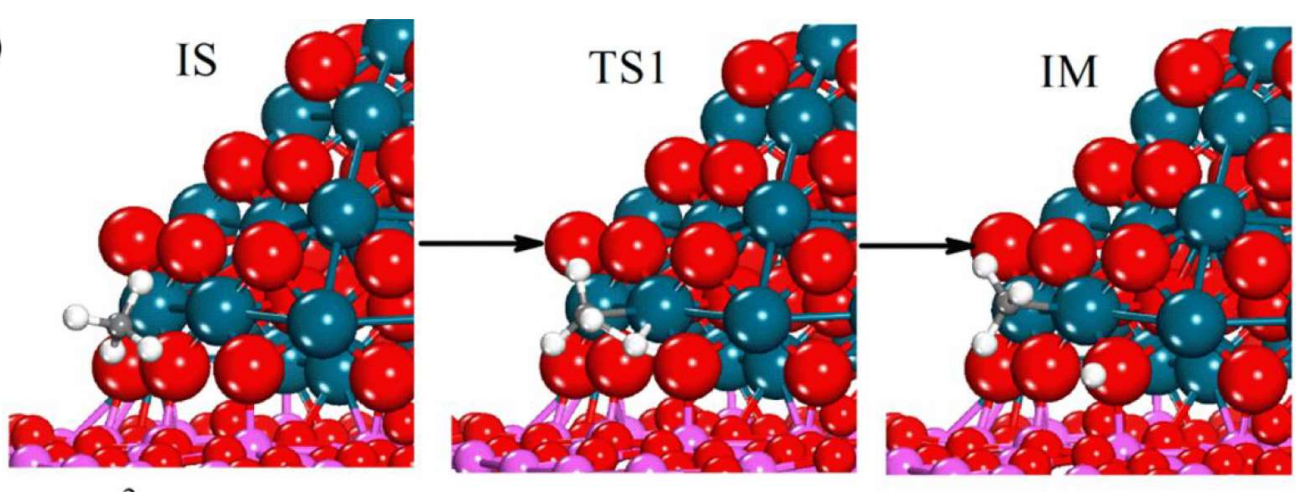

$$
\mathrm{E}_{\mathrm{ads}}^{2}=0.40 \mathrm{eV}
$$

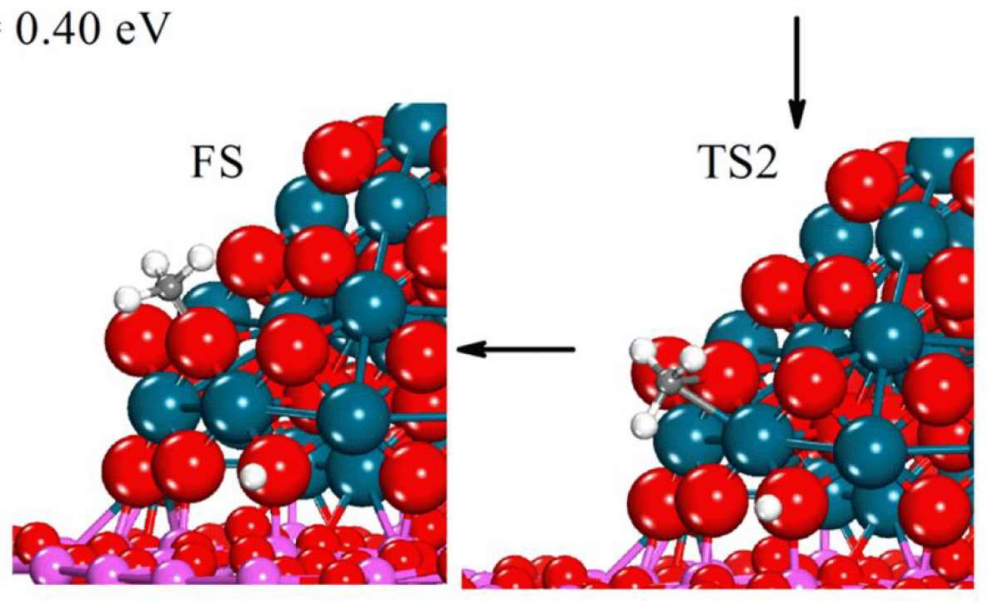

(b)

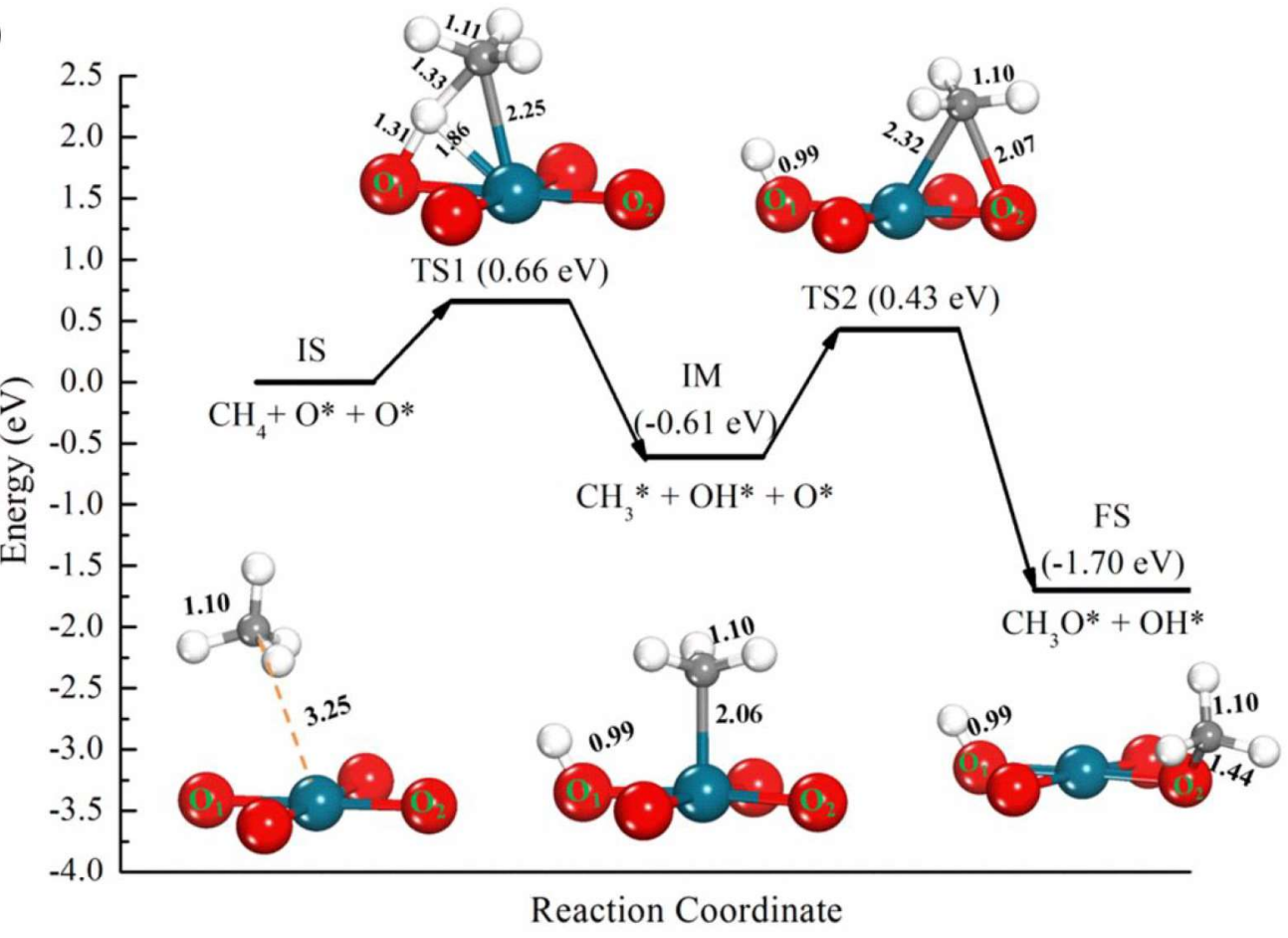

Figure 11. $\mathrm{CH}_{4}$ oxidation $\left(\mathrm{CH}_{4}+\mathrm{O}^{*}+\mathrm{O}^{*} \rightarrow \mathrm{CH}_{3} \mathrm{O}^{*}+\mathrm{OH}^{*}\right)$ on the $\mathrm{Pd}_{30} \mathrm{O}_{44} / \mathrm{Al}_{2} \mathrm{O}_{3}(100)$ catalyst: (a) Structures of the initial state (IS), transition state (TS), intermediate state (IM), and final state (FS). (b) Energy diagram of the reaction pathway on $\mathrm{O}^{*}-\mathrm{O}^{*}$ site pairs (labeled with $\mathrm{O}_{1}-\mathrm{O}_{2}$ ). Color code: $\mathrm{H}$, white; $C$, gray; $O$, red; and $P d$, dark green. 
During the SW-treatment, the methane oxidation performance of the catalyst decreased significantly compared to the fresh catalyst (Table 2 and Fig. 12). Formed bulk $\mathrm{Al}_{2}\left(\mathrm{SO}_{3}\right)_{4}$ and the slight growing of the PdO crystallites likely decreased the activity of the SW-treated catalyst.

Table 2. Light-off temperatures ( $T_{50}$ and $T_{90}$ are temperatures at which the $C H 4$ conversion is $50 \%$ and $90 \%$, respectively) for $\mathrm{CH}_{4}$ oxidation over the fresh, $\mathrm{SW}$-treated and regenerated (Reg. $\mathrm{CH}_{4}$ and Reg. $\mathrm{CH}_{4}+$ Reg. $\left.\mathrm{O}_{2}\left(500^{\circ} \mathrm{C}\right)\right)$ catalysts.

\begin{tabular}{lcc}
\hline Catalyst & $\mathrm{T}_{50}\left[{ }^{\circ} \mathrm{C}\right]$ & $\mathrm{T}_{90}\left[{ }^{\circ} \mathrm{C}\right]$ \\
\hline Fresh & 347 & 412 \\
SW-treated & 448 & 527 \\
Reg. $\mathrm{CH}_{4}$ & 375 & 461 \\
Reg. $\mathrm{CH}_{4}+$ Reg. $\mathrm{O}_{2}\left(500{ }^{\circ} \mathrm{C}\right)$ & 386 & 455 \\
\hline
\end{tabular}

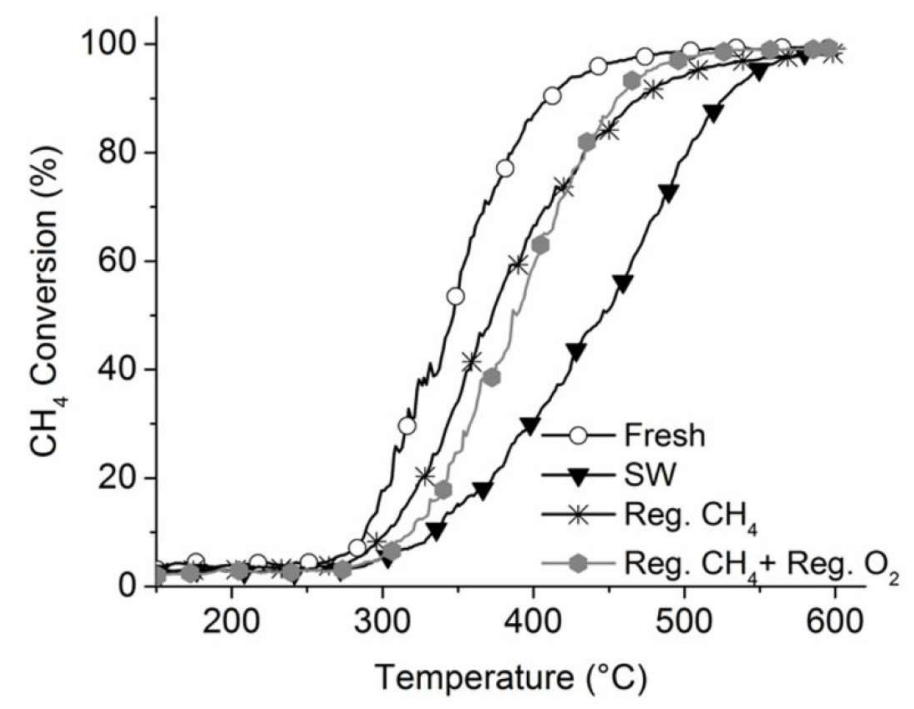

Figure 12. $\mathrm{CH}_{4}$ conversion as a function of temperature for the fresh, $\mathrm{SW}$-treated and after that regenerated catalysts.

For the $\mathrm{CH}_{4}$ decomposition reaction over the 16- $\mathrm{SO}_{3}$ encapsulated $\mathrm{Pd}_{30} \mathrm{O}_{44} / \mathrm{Al}_{2} \mathrm{O}_{3}$ catalyst, the structures of IS, TS and FS, together with the energy diagram of reaction pathway of the $\mathrm{CH}_{4}$ oxidation on $\mathrm{O}^{*}-\mathrm{O}^{*}$ site pairs of the $\left(\mathrm{SO}_{3}\right)_{16} @ \mathrm{Pd}_{30} \mathrm{O}_{44} / \mathrm{Al}_{2} \mathrm{O}_{3}$ catalyst are given in Figure 13. The initial optimized C-Pd distance is $3.65 \AA$ with $E_{a d s}^{2}=0.35 \mathrm{eV}$. Note that the cluster surface is not completely blocked by $\mathrm{SO}_{3}$ enabling $\mathrm{CH}_{4}$ adsorption. At TS, the $\mathrm{C}-\mathrm{H}$ bond has elongated up to $2.01 \AA$ before it binds with an $\mathrm{O}$ atom (labeled with $\mathrm{O}_{3}$ ) of $\mathrm{SO}_{3}$. The bond distances of $\mathrm{H}-\mathrm{O}_{3}, \mathrm{H}-\mathrm{O}_{1} \mathrm{C}-\mathrm{O}_{2}$ (See labels in Figure 13b) are 0.99, 3.13 and $2.46 \AA$, respectively. The activation barrier is found to be $2.01 \mathrm{eV}$, much higher than that of the fresh $\mathrm{Pd}_{30} \mathrm{O}_{44} / \mathrm{Al}_{2} \mathrm{O}_{3}$ catalyst, which indicates chemical inactivity and agrees very well with the experimental results. This is expected based on the geometric (encapsulation) and electronic (charge transfer) properties of the $\left(\mathrm{SO}_{3}\right)_{16} @ \mathrm{Pd}_{30} \mathrm{O}_{44} / \mathrm{Al}_{2} \mathrm{O}_{3}$ catalyst system. 


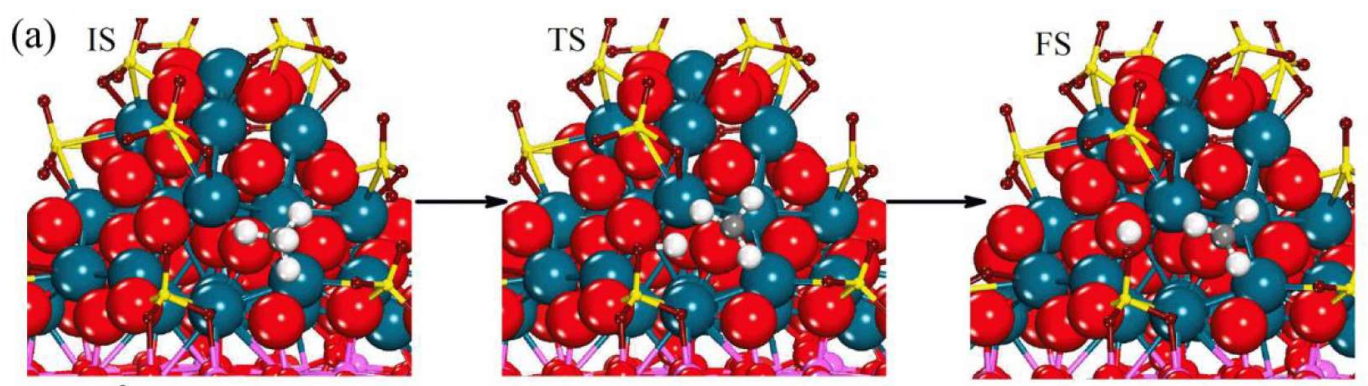

$\mathrm{E}_{\mathrm{ads}}^{2}=0.35 \mathrm{eV}$

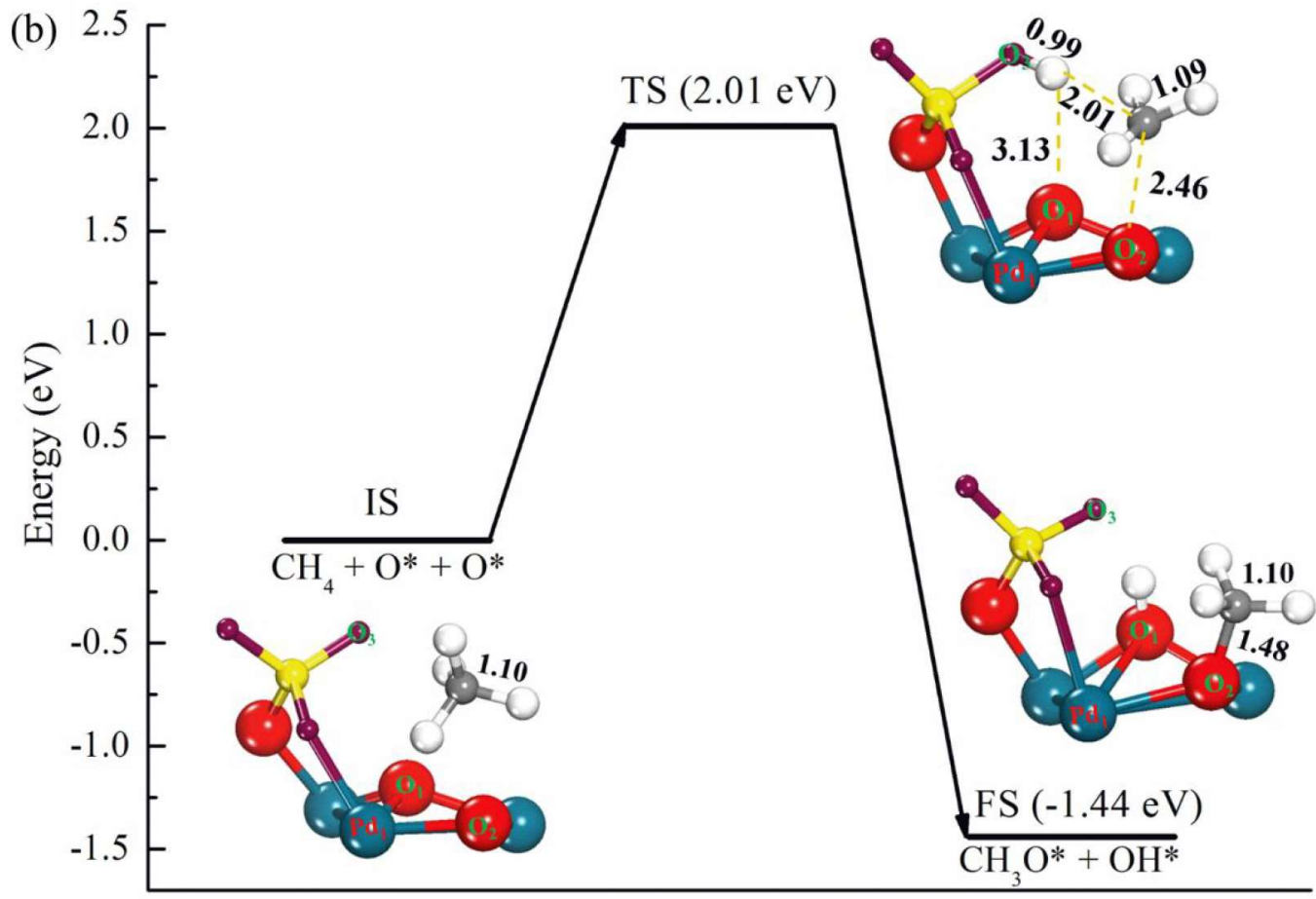

Reaction Coordinate

Figure 13. $\mathrm{CH}_{4}$ oxidation $\left(\mathrm{CH}_{4}+\mathrm{O}^{*}+\mathrm{O}^{*} \rightarrow \mathrm{CH}_{3} \mathrm{O}^{*}+\mathrm{OH}^{*}\right)$ on $\left(\mathrm{SO}_{3}\right)_{16} @ \mathrm{Pd}_{30} \mathrm{O}_{44} / \mathrm{Al}_{2} \mathrm{O}_{3}(100):(a)$

Structures of the initial state (IS), transition state (TS), intermediate state (IM), and final state (FS). (b) Energy diagram of the reaction pathway on $\mathrm{O}^{*} \mathrm{O}^{*}$ site pairs (labeled with $\mathrm{O}_{1}-\mathrm{O}_{2}$ ). Color code: $\mathrm{S}$, yellow; $H$, white $C$, gray; $O$ (cluster), red; $O$ (incoming), magenta; and $P d$, dark green.

$\mathrm{CH}_{4}$ conversion is partially restored by the regeneration treatment under $\mathrm{CH}_{4}$ conditions (Table 2 and Fig. 12). No full recovery was achieved, probably due to the small amount of remaining bulk $\mathrm{Al}_{2}\left(\mathrm{SO}_{4}\right)_{3}$, the formation of sulfur species on the palladium particles, and the partial reduction of $\mathrm{PdO}$ particles to $\mathrm{Pd}$ during the regeneration treatment. To reoxidize $\mathrm{Pd}$ to $\mathrm{PdO}$, the catalyst was further regenerated under $\mathrm{O}_{2}$ conditions and the catalyst further regenerated at $500{ }^{\circ} \mathrm{C}$ was selected for the performance tests to make sure of total reoxidation of $\mathrm{Pd}$ and at the same time to avoid possible sintering of the $\mathrm{Pd} / \mathrm{PdO}$ particles at higher temperatures. According to our earlier studies [42], changes in the noble metal particles start at 555 the regenerated (in $\mathrm{CH}_{4}$ conditions) catalyst (Table 2 and Fig. 11). Thus, a small amount of bulk $556 \mathrm{Al}_{2}\left(\mathrm{SO}_{4}\right)_{3}$ seems to have a stronger effect on the catalyst performance than the state of palladium $557(\mathrm{Pd} / \mathrm{PdO})$. 
559 Sulfur deactivation and regeneration behavior of the $\mathrm{Pd} / \mathrm{Al}_{2} \mathrm{O}_{3}$ natural gas oxidation catalyst was studied. 560 The fresh and treated catalysts were characterized by TEM, XRD, FT-IR, and performance tests. The 561 experimental characterizations were complemented by performing DFT-based simulations of PdO catalyst model structures with and without interacting $\mathrm{SO}_{\mathrm{x}}$ species. During the sulfur treatment, $\mathrm{PdO}$ crystallites grew slightly. In addition, the formation of a small amount of bulk $\mathrm{Al}_{2}\left(\mathrm{SO}_{4}\right)_{3}$ was observed. Based on the DFT calculations, $\mathrm{SO}_{\mathrm{x}}$ species showed a strong interaction with the catalyst. The saturation adsorption of $\left(\mathrm{SO}_{3}\right)_{\mathrm{n}}$ on $\mathrm{Pd}_{30} \mathrm{O}_{44} / \mathrm{Al}_{2} \mathrm{O}_{3}$ was reached at $n=16$, corresponding to the case where $\mathrm{Pd}_{30} \mathrm{O}_{44}$ is mostly encapsulated by $\mathrm{SO}_{x}$. The catalyst structure retains, however, the original internal Pd-O geometry. During $\mathrm{PdO}$ particles are partly reduced to metallic $\mathrm{Pd}$. In addition to $\mathrm{Al}_{2}\left(\mathrm{SO}_{4}\right)_{3}$, sulfur species on the Pd particles were observed due to the migration of sulfate species from the support on the Pd particles during regeneration. To reoxidize $\mathrm{Pd}$, the catalyst was further regenerated under $\mathrm{O}_{2}$ conditions at various temperatures. After further regeneration, the catalyst had still a small amount of bulk $\mathrm{Al}_{2}\left(\mathrm{SO}_{4}\right)_{3}$ but sulfur species on the palladium particles disappeared.

The performance of the catalysts for $\mathrm{CH}_{4}$ oxidation was studied theoretically and experimentally. Sulfur treatment and encapsulation of $\mathrm{PdO}$ cluster by $\mathrm{SO}_{3}$ decreased the catalyst activity to convert $\mathrm{CH}_{4}$. The conversion could be partly restored by the regeneration treatment in $\mathrm{CH}_{4}$ conditions. Due to remaining bulk $\mathrm{Al}_{2}\left(\mathrm{SO}_{4}\right)_{3}$, the formation of sulfur species on the $\mathrm{Pd}$ particles, and the partial reduction of $\mathrm{PdO}$ particles to $\mathrm{Pd}$ during the regeneration treatment, no full recovery was achieved. After the further regeneration treatment under $\mathrm{O}_{2}$ conditions (to reoxidize $\mathrm{Pd}$ to $\mathrm{PdO}$ ), the $\mathrm{CH}_{4}$ conversation was at the same level with the regenerated (in $\mathrm{CH}_{4}$ conditions) catalyst. Thus, bulk $\mathrm{Al}_{2}\left(\mathrm{SO}_{4}\right)_{3}$ and sulfur species on the Pd particles seem to have a stronger effect on the catalyst performance than the state of palladium $(\mathrm{Pd} / \mathrm{PdO})$. 
594

595 The Strategic funding tool of TUT Foundation is thanked for funding. The DFT calculations were

596 performed at CSC - IT Center for Science, Espoo, Finland. We acknowledge the provision of facilities

597 and technical support by Aalto University at OtaNano - Nanomicroscopy Center (Aalto-NMC). 


\section{References:}

[1] R. van Basshuysen (Ed.), Natural Gas and Renewable Methane for Powertrains, Springer International Publishing, Switzerland, 2016, p. 482. doi:10.1007/978-3-319-23225-6.

[2] R.J. Farrauto, J.K. Lampert, M.C. Hobson, E.M. Waterman, Thermal decomposition and reformation of PdO catalysts; support effects, Appl. Catal. B Environ. 6 (1995) 263-270. doi:10.1016/0926-3373(95)00015-1.

[3] P. Gélin, M. Primet, Complete oxidation of methane at low temperature over noble metal based catalysts: a review, Appl. Catal. B Environ. 39 (2002) 1-37. doi:10.1016/S0926-3373(02)00076-0.

[4] S.K. Matam, M.H. Aguirre, A. Weidenkaff, D. Ferri, Revisiting the problem of active sites for methane combustion on $\mathrm{Pd} / \mathrm{Al}_{2} \mathrm{O}_{3}$ by operando XANES in a lab-scale fixed-bed reactor, J. Phys. Chem. C. 114 (2010) 9439-9443. doi:10.1021/jp1019697.

[5] C.H. Bartholomew, Mechanisms of catalyst deactivation, Appl. Catal. A Gen. 212 (2001) 17-60. doi:10.1016/S0926-860X(00)00843-7.

[6] A.K. Datye, J. Bravo, T.R. Nelson, P. Atanasova, M. Lyubovsky, L. Pfefferle, Catalyst microstructure and methane oxidation reactivity during the $\mathrm{Pd} \leftrightarrow \mathrm{PdO}$ transformation on alumina supports, Appl. Catal. A Gen. 198 (2000) 179-196. doi:10.1016/S0926-860X(99)00512-8.

[7] M. Lyubovsky, L. Pfefferle, Complete methane oxidation over Pd catalyst supported on $\alpha$-alumina. Influence of temperature and oxygen pressure on the catalyst activity, Catal. Today. 47 (1999) 2944. doi:10.1016/S0920-5861(98)00281-8.

[8] A. Baylet, P. Marecot, D. Duprez, P. Castellazzi, G. Groppi, P. Forzatti, In situ Raman and in situXRD analysis of $\mathrm{PdO}$ reduction and $\mathrm{Pd}^{0}$ oxidation supported on $\gamma-\mathrm{Al}_{2} \mathrm{O}_{3}$ catalyst under different atmospheres, Phys. Chem. Chem. Phys. 13 (2011) 4607-4613. doi:10.1039/C0CP01331E.

[9] A.K. Neyestanaki, F. Klingstedt, T. Salmi, D.Y. Murzin, Deactivation of postcombustion catalysts, a review, Fuel. 83 (2004) 395-408. doi:10.1016/j.fuel.2003.09.002.

[10] J. Lampert, M. Kazi, R. Farrauto, Palladium catalyst performance for methane emissions abatement from lean burn natural gas vehicles, Appl. Catal. B Environ. 14 (1997) 211-223. doi:10.1016/S0926-3373(97)00024-6.

[11] A.T. Gremminger, H.W. Pereira de Carvalho, R. Popescu, J.-D. Grunwaldt, O. Deutschmann, Influence of gas composition on activity and durability of bimetallic $\mathrm{Pd}-\mathrm{Pt} / \mathrm{Al}_{2} \mathrm{O}_{3}$ catalysts for total oxidation of methane, Catal. Today. 258 (2015) 470-480. doi:10.1016/j.cattod.2015.01.034.

[12] D.L. Mowery, R.L. McCormick, Deactivation of alumina supported and unsupported PdO methane oxidation catalyst: the effect of water on sulfate poisoning, Appl. Catal. B Environ. 34 (2001) 287297. doi:10.1016/S0926-3373(01)00222-3.

[13] O. Kröcher, M. Widmer, M. Elsener, D. Rothe, Adsorption and Desorption of SOx on Diesel Oxidation Catalysts, Ind. Eng. Chem. Res. 48 (2009) 9847-9857. doi:10.1021/ie900882p.

[14] N.M. Kinnunen, J.T. Hirvi, K. Kallinen, T. Maunula, M. Keenan, M. Suvanto, Case study of a modern lean-burn methane combustion catalyst for automotive applications: What are the deactivation and regeneration mechanisms?, Appl. Catal. B Environ. 207 (2017) 114-119. doi:10.1016/j.apcatb.2017.02.018.

[15] N. Luckas, F. Viñes, M. Happel, A. Desikusumastuti, J. Libuda, A. Görling, Density Functional Calculations and IR Reflection Absorption spectroscopy on the interaction of $\mathrm{SO}_{2}$ with oxidesupported Pd nanoparticles, J. Phys. Chem. C. 114 (2010) 13813-13824. doi:10.1021/jp105097z.

[16] N. Luckas, K. Gotterbarm, R. Streber, M.P.A. Lorenz, O. Hofert, F. Vines, C. Papp, A. Gorling, H.-P. Steinruck, Adsorption and reaction of $\mathrm{SO}_{2}$ on clean and oxygen precovered $\mathrm{Pd}(100)$-a combined HR-XPS and DF study, Phys. Chem. Chem. Phys. 13 (2011) 16227-16235. doi:10.1039/C1CP21694E.

[17] K. Gotterbarm, N. Luckas, O. Höfert, M.P.A. Lorenz, R. Streber, C. Papp, F. Viñes, H.-P. Steinrück, A. Görling, Kinetics of the sulfur oxidation on palladium: A combined in situ X-ray photoelectron spectroscopy and density-functional study, J. Chem. Phys. 136 (2012) 94702. doi:10.1063/1.3687676. 
[18] H.N. Sharma, V. Sharma, T. Hamzehlouyan, W. Epling, A.B. Mhadeshwar, R. Ramprasad, SOx Oxidation kinetics on $\mathrm{Pt}(111)$ and $\mathrm{Pd}(111)$ : first-principles computations meet microkinetic modeling, J. Phys. Chem. C. 118 (2014) 6934-6940. doi:10.1021/jp501538v.

[19] F. Arosio, S. Colussi, G. Groppi, A. Trovarelli, Regeneration of S-poisoned $\mathrm{Pd} / \mathrm{Al}_{2} \mathrm{O}_{3}$ and $\mathrm{Pd} / \mathrm{CeO} 2 / \mathrm{A} 12 \mathrm{O} 3$ catalysts for the combustion of methane, Top. Catal. 42 (2007) 405-408. doi:10.1007/s11244-007-0214-y.

[20] http://www.cp2k.org, (3.11.2017).

[21] J. VandeVondele, M. Krack, F. Mohamed, M. Parrinello, T. Chassaing, J. Hutter, Quickstep: Fast and accurate density functional calculations using a mixed Gaussian and plane waves approach, Comput. Phys. Commun. 167 (2005) 103-128. doi:10.1016/j.cpc.2004.12.014.

[22] J.P. Perdew, K. Burke, M. Ernzerhof, Generalized Gradient Approximation Made Simple, Phys. Rev. Lett. 77 (1996) 3865-3868. doi:10.1103/PhysRevLett.77.3865.

[23] S. Goedecker, M. Teter, J. Hutter, Separable dual-space Gaussian pseudopotentials, Phys. Rev. B. 54 (1996) 1703-1710. doi: 10.1103/PhysRevB.54.1703.

[24] J. VandeVondele, J. Hutter, Gaussian basis sets for accurate calculations on molecular systems in gas and condensed phases, J. Chem. Phys. 127 (2007) 114105. doi:10.1063/1.2770708.

[25] B.G. Lippert, J. Hutter and M. Parrinello, A hybrid Gaussian and plane wave density functional scheme, Mol. Phys. 92 (1997) 477-488. doi:10.1080/002689797170220.

[26] S. Grimme, Semiempirical GGA-type density functional constructed with a long-range dispersion correction, J. Comput. Chem. 27 (2006) 1787-1799. doi:10.1002/jcc.20495.

[27] W. Tang and E. Seanville and G. Henkelman, A grid-based Bader analysis algorithm without lattice bias, J. Phys. Condens. Matter. 21 (2009) 84204. http://stacks.iop.org/0953$8984 / 21 / \mathrm{i}=8 / \mathrm{a}=084204$.

[28] R.F.W. Bader, A quantum theory of molecular structure and its applications, Chem. Rev. 91 (1991) 893-928. doi:10.1021/cr00005a013.

[29] G. Henkelman, B.P. Uberuaga, H. Jónsson, A climbing image nudged elastic band method for finding saddle points and minimum energy paths, J. Chem. Phys. 113 (2000) 9901-9904. doi:10.1063/1.1329672.

[30] M. Digne, P. Sautet, P. Raybaud, P. Euzen, H. Toulhoat, Use of DFT to achieve a rational understanding of acid-basic properties of $\gamma$-alumina surfaces, J. Catal. 226 (2004) 54-68. doi:10.1016/j.jcat.2004.04.020.

[31] A.F. Lee, K. Wilson, R.M. Lambert, C.P. Hubbard, R.G. Hurley, R.W. McCabe, H.S. Gandhi, The Origin of SO2 Promotion of Propane Oxidation over $\mathrm{Pt}_{2} / \mathrm{Al}_{2} \mathrm{O}_{3}$ Catalysts, J. Catal. 184 (1999) 491498. doi:10.1006/jcat.1999.2454.

[32] M. Honkanen, M. Kärkkäinen, T. Kolli, O. Heikkinen, V. Viitanen, L. Zeng, H. Jiang, K. Kallinen, M. Huuhtanen, R.L. Keiski, J. Lahtinen, E. Olsson, M. Vippola, Accelerated deactivation studies of the natural-gas oxidation catalyst - Verifying the role of sulfur and elevated temperature in catalyst aging, Appl. Catal. B Environ. 182 (2016) 439-448. doi:10.1016/j.apcatb.2015.09.054.

[33] H. Abdulhamid, E. Fridell, J. Dawody, M. Skoglundh, In situ FTIR study of $\mathrm{SO}_{2}$ interaction with $\mathrm{Pt} / \mathrm{BaCO}_{3} / \mathrm{Al}_{2} \mathrm{O}_{3} \mathrm{NO}_{\mathrm{x}}$ storage catalysts under lean and rich conditions, J. Catal. 241 (2006) 200210. doi:10.1016/j.jcat.2006.04.034.

[34] H. Mahzoul, L. Limousy, J.. Brilhac, P. Gilot, Experimental study of $\mathrm{SO}_{2}$ adsorption on bariumbased NOx adsorbers, J. Anal. Appl. Pyrolysis. 56 (2000) 179-193. doi:10.1016/S01652370(00)00090-5.

[35] S. Colussi, F. Arosio, T. Montanari, G. Busca, G. Groppi, A. Trovarelli, Study of sulfur poisoning on $\mathrm{Pd} / \mathrm{Al}_{2} \mathrm{O}_{3}$ and $\mathrm{Pd} / \mathrm{CeO}_{2} / \mathrm{Al}_{2} \mathrm{O}_{3}$ methane combustion catalysts, Catal. Today. 155 (2010) 59-65. doi:10.1016/j.cattod.2009.02.019.

[36] T.-C. Yu, H. Shaw, The effect of sulfur poisoning on methane oxidation over palladium supported on $\gamma$-alumina catalysts, Appl. Catal. B Environ. 18 (1998) 105-114. doi:10.1016/S09263373(98)00031-9.

[37] M. Konsolakis, I.V. Yentekakis, G. Pekridis, N. Kaklidis, A.C. Psarras, G.E. Marnellos, Insights into the role of $\mathrm{SO}_{2}$ and $\mathrm{H}_{2} \mathrm{O}$ on the surface characteristics and de- $\mathrm{N}_{2} \mathrm{O}$ efficiency of $\mathrm{Pd} / \mathrm{Al}_{2} \mathrm{O}_{3}$ catalysts during $\mathrm{N}_{2} \mathrm{O}$ decomposition in the presence of $\mathrm{CH}_{4}$ and $\mathrm{O}_{2}$ excess, Appl. Catal. B Environ. 
138 (2013) 191-198. doi:10.1016/j.apcatb.2013.02.038.

[38] P. Gélin, L. Urfels, M. Primet, E. Tena, Complete oxidation of methane at low temperature over Pt and Pd catalysts for the abatement of lean-burn natural gas fuelled vehicles emissions: influence of water and sulphur containing compounds, Catal. Today. 83 (2003) 45-57. doi:10.1016/S09205861(03)00215-3.

[39] C. J. Zhang, P. Hu, The possibility of single $\mathrm{C}-\mathrm{H}$ bond activation in $\mathrm{CH}_{4}$ on a $\mathrm{MoO}_{3}$-supported $\mathrm{Pt}$ catalyst: A density functional theory study, J Chem. Phys. 116 (2002) 4281. doi: 10.1063/1.1449942.

[40] A.A. Latimer, A.R. Kulkarni, H. Aljama, J.H. Montoya, J.S. Yoo, C. Tsai, F. Abild-Pedersen, F. Studt, J.K. Norskov, Understanding trends in C-H bond activation in heterogeneous catalysis, Nat Mater. 16 (2017) 225-229. http://dx.doi.org/10.1038/nmat4760.

[41] Y.-H. Chin, C. Buda, M. Neurock, E. Iglesia, Consequences of metal-oxide interconversion for C$\mathrm{H}$ bond activation during $\mathrm{CH}_{4}$ reactions on Pd catalysts, J. Am. Chem. Soc. 135 (2013) 1542515442. doi:10.1021/ja405004m.

[42] M. Honkanen, T.W. Hansen, H. Jiang, M. Kärkkäinen, M. Huuhtanen, O. Heikkinen, K. Kallinen, J. Lahtinen, R.L. Keiski, J.B. Wagner, M. Vippola, Electron microscopic studies of natural gas oxidation catalyst - Effects of thermally accelerated aging on catalyst microstructure, J. Catal. 349 (2017) 19-29. doi:10.1016/j.jcat.2017.03.003. 